OPEN ACCESS

Edited by:

Carla R. Taddei,

University of São Paulo, Brazil

Reviewed by:

Silvia Daher,

Federal University of São Paulo, Brazi Alison Jane Carey,

Queensland University of Technology,

Australia

*Correspondence:

Fengxia Xue

fengxiaxue1962@gmail.com

${ }^{\dagger}$ These authors have contributed equally to this work

Specialty section:

This article was submitted to Microbiome in Health and Disease, a section of the journal

Frontiers in Cellular

and Infection Microbiology

Received: 23 September 2020 Accepted: 18 November 2020

Published: 23 December 2020

Citation:

$L i H$, Zang $Y$, Wang $C, L i H$, Fan $A$,

Han $C$ and Xue $F$ (2020) The Interaction Between Microorganisms,

Metabolites, and Immune System in the Female Genital Tract Microenvironment. Front. Cell. Infect. Microbiol. 10:609488. doi: 10.3389/fcimb.2020.609488

\section{The Interaction Between} Microorganisms, Metabolites, and Immune System in the Female Genital Tract Microenvironment

\author{
Huanrong $\mathrm{Li}^{1,2 \dagger}$, Yuqin Zang ${ }^{1,2 \dagger}$, Chen Wang ${ }^{1,2}$, Huiyang $\mathrm{Li}^{1,2}$, Aiping Fan ${ }^{1,2}$, Cha Han ${ }^{1,2}$ \\ and Fengxia Xue ${ }^{1,2 *}$

\begin{abstract}
${ }^{1}$ Department of Gynecology and Obstetrics, Tianiin Medical University General Hospital, Tianiin, China, ${ }^{2}$ Department of Gynecology and Obstetrics, Tianjin Key Laboratory of Female Reproductive Health and Eugenic, Tianjin Medical University General Hospital, Tianjin, China
\end{abstract}

The female reproductive tract microenvironment includes microorganisms, metabolites, and immune components, and the balance of the interactions among them plays an important role in maintaining female reproductive tract homeostasis and health. When any one of the reproductive tract microorganisms, metabolites, or immunity is out of balance, it will affect the other two, leading to the occurrence and development of diseases and the appearance of corresponding symptoms and signs, such as infertility, miscarriage, premature delivery, and gynecological tumors caused by infectious diseases of the reproductive tract. Nutrients in the female reproductive tract provide symbiotic and pathogenic microorganisms with a source of nutrients for their own reproduction and utilization. At the same time, this interaction with the host forms a variety of metabolites. Changes in metabolites in the host reproductive tract are related not only to the interaction between the host and microbiota under dysbiosis but also to changes in host immunity or the environment, all of which will participate in the pathogenesis of diseases and lead to disease-related phenotypes. Microorganisms and their metabolites can also interact with host immunity, activate host immunity, and change the host immune status and are closely related to persistent genital pathogen infections, aggravation of infectious diseases, severe pregnancy outcomes, and even gynecological cancers. Therefore, studying the interaction between microorganisms, metabolites, and immunity in the reproductive tract cannot only reveal the pathogenic mechanisms that lead to inflammation of the reproductive tract, adverse pregnancy outcomes and tumorigenesis but also provide a basis for further research on the diagnosis and treatment of targets.

Keywords: microenvironment, female genital tract, immunity, metabolites, microbiota

\section{INTRODUCTION}

Different from the high diversity of the gastrointestinal tract, the female genital tract microbiome has low diversity, and it changes dynamically through the female menstrual cycle (Consortium, 2012; Chen et al., 2017). Most microbes have a symbiotic relationship with the host. Accounting for $90-95 \%$ of the total bacterial biomass, Lactobacillus spp. represents a healthy female genital tract microbiota 
that produces lactic acid to maintain an acidic microenvironment. It can also inhibit pathogens through competition, adhesion prevention, and the secretion of antibacterial and immunomodulatory substances (Anahtar et al., 2018; Van der Veer et al., 2019). Vaginitis, cervicitis, and pelvic inflammatory disease (PID) will occur if pathogenic bacteria surpass lactobacilli in the female genital tract and can cause uncomfortable symptoms such as increased vulvovaginal discharge, itching, odor, and lower abdominal pain (Workowski and Bolan, 2015). However, there are differences in the microbes between subjects and in the ability of the host to resist dysbiosis that may be related to race, diet, age, living habits, immunity, disease susceptibility, and genetic polymorphism (Consortium, 2012; Anahtar et al., 2018; Chu et al., 2018; Serrano et al., 2019). Furthermore, the dominance of different microflora is not necessarily related to symptoms because partial non-Lactobacillusdominant women do not experience uncomfortable symptoms of vulvovaginitis; hence, we cannot define disease by the number of bacteria alone, and we cannot define dysbiosis without the internal milieu of the host and disease environment (Anahtar et al., 2018; Scott et al., 2019).

Metabolites in the reproductive tract play an important role in female genital tract inflammation, pregnancy and tumors and can be considered biomarkers of disease severity, diagnosis, and prognosis (Ghartey et al., 2015; McMillan et al., 2015; Ilhan et al., 2019; Song et al., 2019). Metabolites in the female reproductive tract are the substrates, intermediates and byproducts of biochemical reactions caused by the interaction of human nutrients and bacteria, reflecting downstream events of gene expression (Altmäe et al., 2014; McMillan et al., 2015; Turkoglu et al., 2016; Watson and Reid, 2018) (Figure 1). These metabolites are better than genome, transcriptome, and proteome substances at predicting the disease phenotype (Altmäe et al., 2014). Genital infections, adverse pregnancy outcomes, and cancers possess different metabolic signatures that are often accompanied by dysbiosis of the female genital tract (Ghartey et al., 2015; Ceccarani et al., 2019; Ilhan et al., 2019). The metabolic pathways affected by these metabolites mainly include amino acids, carbohydrates, and lipid metabolism, which are closely related to life activities (Srinivasan et al., 2015). These activities further affect host cell function, immunity, and disease susceptibility and help maintain the balance of the host's reproductive tract microenvironment.

The host's innate and adaptive immune systems perform complex interactions with microorganisms and metabolites (Agostinis et al., 2019; Delgado-Diaz et al., 2019). Microbial ligands bind to host receptors to produce inflammatory factors, chemokines and antimicrobial products to regulate the immune response of the reproductive tract (Hooper et al., 2012).Vaginal dysbiosis cannot only directly cause vaginal epithelial injury through pathogens (Tao et al., 2019), but also indirectly cause vaginal epithelial injury through immune components, which in turn release metabolites into the microenvironment (Olive and Sassetti, 2016; Serrano et al., 2019). This metabolite may be ingested by the vaginal microbiota, leading to increased microbial metabolism, which is beneficial to the growth and reproduction of the microbiota (Serrano et al., 2019). The local competition between the host, pathogen and different immune cells for metabolic precursors will also affect the ability of immune cells to respond effectively to infection, affecting the growth and immunogenicity of the pathogen and further affecting the host response (Hooper et al., 2012; Olive and Sassetti, 2016; Postler and Ghosh, 2017). Therefore, the interaction between microorganisms, metabolites, and immunity in the host reproductive tract microenvironment plays an important role in maintaining the balance of the reproductive tract (Pruski et al., 2018). An imbalance in any part will result in host phenotype changes, disease, and even serious complications. Therefore, this article intended to review the relationship and importance of

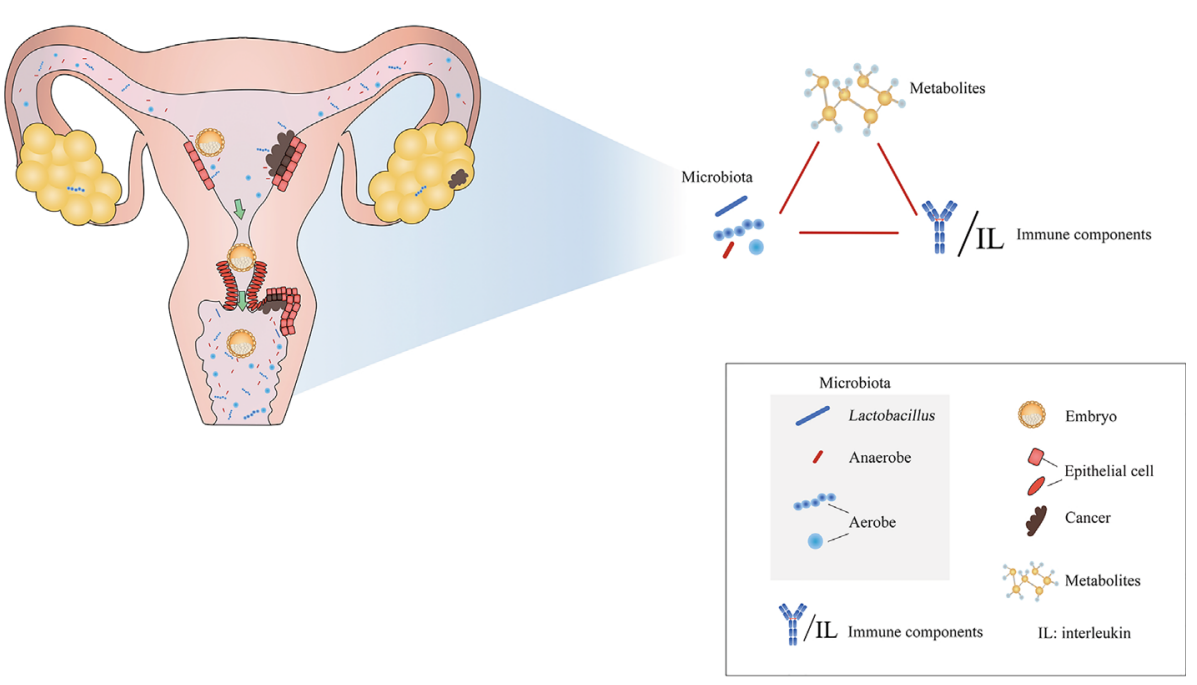

FIGURE 1 | Microenvironmental disorders of the female reproductive tract are closely related to inflammations, adverse pregnancy outcomes, and tumors. Modified from Paweł Łaniewski et al. (2020). 
reproductive tract microorganisms, metabolites, and immunity to obtain a deeper understanding of the reproductive tract microenvironment, reproductive tract diseases and adverse reproductive tract outcomes.

\section{NORMAL VAGINAL MICROENVIRONMENT}

The vaginal microbiota community state types (CSTs) of women of childbearing age are divided into five categories (Ravel et al., 2011). CST I is dominated by Lactobacillus crispatus; CST II by $L$. gasseri; CST V by L. jensenii; and CST III by L. iners. CST IV belongs to the Lactobacillus-deficient type, which is dominated by anaerobic bacteria (classified by bacterial vaginosis, BV), partial aerobic bacteria (classified by aerobic vaginitis, AV) or a modest proportion of Lactobacillus spp. (Gajer et al., 2012). The vaginal microbiota is dynamic and occasionally transitions to an intermediate state or a disease state in most normal nonpregnant women. A high Nugent score does not indicate the disease status or microecological disorders (Gajer et al., 2012). The internal milieu of the host will make the microbiota return to a stable state. Factors that cause vaginal microbiota changes are primarily related to menstruation. Others include sexual intercourse, hormonal contraception, antimicrobial agents, use of lubricants, and vaginal douching, but they have less impact than menstrual periods and cause changes in the vaginal microbiota for a shorter duration (Gajer et al., 2012; Mitchell et al., 2012). In addition, in a few women, the vaginal CST does not change with the menstrual cycle and hormonal contraception, but further study by future researchers is needed to determine whether it is related to the metabolic function of bacteria (Gajer et al., 2012; Song et al., 2020).

Lactobacillus abundance in the female genital tract is strongly positively correlated with lactate and 4-hydroxyphenylacetate and correlated to a lesser extent with isoleucine, leucine, tryptophan, phenylalanine, aspartate, dimethylamine, sarcosine and pi-methylhistidine, all of which are typically associated with vaginal health (Srinivasan et al., 2015; Ceccarani et al., 2019) (Table 1). L. crispatus and L. jensenii have similar metabolic patterns (Srinivasan et al., 2015), while, L. crispatus and L. iners have different metabolic characteristics (Pruski et al., 2018). For example, studies have found that the genome of L. crispatus is almost twice that of $L$. iners (France et al., 2016). However, the carbon metabolism of $L$. iners is fermented by fewer compounds than L. crispatus (Pruski et al., 2018). When the dominant bacteria are L. crispatus and/or L. jensenii, most of the metabolites in the vagina are amino acids and dipeptide, such as higher levels of ornithine, lysine, glycylproline, phenylalanine (Srinivasan et al., 2015). Similar to BV-related flora, L. iners are correlated with amino acid catabolites, such as higher levels of

TABLE 1 I Current existing articles analyzing the correlation between the genital tract flora and metabolites in normal non-pregnant women of reproductive age.

\begin{tabular}{|c|c|c|c|c|c|}
\hline Year & Author & Population & Sample & CST & Metabolites \\
\hline 2019 & $\begin{array}{l}\text { (Ceccarani } \\
\text { et al., } \\
\text { 2019) }\end{array}$ & $\begin{array}{l}\text { Healthy women }(n=21) \text {, women } \\
\text { with } B V(n=20) \text { and women with } \\
\text { Chlamydia trachomatis infection } \\
(n=20)\end{array}$ & $\begin{array}{l}\text { Vaginal } \\
\text { swabs }\end{array}$ & $\begin{array}{l}\text { Contains all } \\
\text { Lactobacillus spp. } \\
\text { without } \\
\text { distinguishing CST }\end{array}$ & $\begin{array}{l}\text { High levels of lactate, 4-hydroxyphenylacetate, isoleucine, leucine, tryptophan, } \\
\text { phenylalanine, aspartate, dimethylamine, sarcosine and pi-methylhistidine }\end{array}$ \\
\hline 2018 & $\begin{array}{l}\text { (Parolin } \\
\text { et al., } \\
\text { 2018) }\end{array}$ & $\begin{array}{l}\text { Healthy women }(n=22) \text {, women } \\
\text { with Chlamydia trachomatis } \\
\text { infection }(n=20) \text {, and women with } \\
\text { BV }(n=19)\end{array}$ & $\begin{array}{l}\text { Vaginal } \\
\text { swabs }\end{array}$ & $\begin{array}{l}\text { Contains all } \\
\text { Lactobacillus spp. } \\
\text { without } \\
\text { distinguishing CST }\end{array}$ & $\begin{array}{l}\text { Higher levels of lactate, 4-hydroxyphenylacetate, diverse amino acids } \\
\text { (phenylalanine, glutamate, leucine, threonine, tryptophan, aspartate) and } \\
\text { amino acid derivatives(sarcosine) }\end{array}$ \\
\hline \multirow[t]{5}{*}{2015} & $\begin{array}{l}\text { (Srinivasan } \\
\text { et al., } \\
\text { 2015) }\end{array}$ & $\begin{array}{l}\text { Women with BV }(n=40) \text { and } \\
\text { women without BV }(n=20)\end{array}$ & $\begin{array}{l}\text { Vaginal } \\
\text { fluid }\end{array}$ & CST-I & $\begin{array}{l}\text { 1) Higher levels of sugars (maltose, maltotriose, and maltohexose), lipid } \\
\text { metabolism biochemicals (such as arachidonate and carnitine), amino acids } \\
\text { (ornithine, lysine), dipeptide (glycylproline, phenylalanine) as well as lactate, } \\
\text { and urea } \\
\text { 2) Lower levels of } \mathrm{N} \text {-acetylneuraminate, succinate, the carnitine precursor } \\
\text { deoxycarnitine, the eicosanoid } 12 \text {-hydroxyeicosatetraenoic acid, the fatty acid } \\
\text { 13-hydroxyoctadecadienoic acid, the nucleobase uracil, and glutathione }\end{array}$ \\
\hline & & & & CST-III & $\begin{array}{l}\text { 1) Higher levels of proline, threonine, aspartate, serine, and valinylglutamate } \\
\text { 2) Lower levels of glutamate and glycylleucine }\end{array}$ \\
\hline & & & & CST-V & Same as CST-I: \\
\hline & & & & & $\begin{array}{l}\text { 1) Higher levels of sugars (maltose, maltotriose, and maltohexose), lipid } \\
\text { metabolism biochemicals (such as arachidonate and carnitine), amino acids } \\
\text { (ornithine, lysine), dipeptide (glycylproline, phenylalanine) as well as lactate, } \\
\text { and urea }\end{array}$ \\
\hline & & & & & $\begin{array}{l}\text { 2) Lower levels of } N \text {-acetylneuraminate, succinate, the carnitine precursor } \\
\text { deoxycarnitine, the eicosanoid } 12 \text {-hydroxyeicosatetraenoic acid, the fatty acid } \\
\text { 13-hydroxyoctadecadienoic acid, the nucleobase uracil, and glutathione }\end{array}$ \\
\hline 2015 & $\begin{array}{l}\text { (McMillan } \\
\text { et al., } \\
\text { 2015) }\end{array}$ & $\begin{array}{l}\text { Pregnant women }(n=67) \text { and non- } \\
\text { pregnant women }(n=64)\end{array}$ & $\begin{array}{l}\text { Vaginal } \\
\text { fluid }\end{array}$ & CST-1 & Higher levels of succinate \\
\hline 2012 & $\begin{array}{l}\text { (Gajer } \\
\text { et al., } \\
\text { 2012) }\end{array}$ & Reproductive age women $(n=32)$ & $\begin{array}{l}\text { Vaginal } \\
\text { swabs }\end{array}$ & CST-III & $\begin{array}{l}\text { 1) Higher levels of lactate } \\
\text { 2) Lower levels of succinate and acetate }\end{array}$ \\
\hline
\end{tabular}

CST, Community state types; BV, bacterial vaginosis. 
proline, threonine, aspartate, serine, and valinylglutamate (Srinivasan et al., 2015). In addition, L. iners often has a symbiotic relationship with $G$. vaginalis, and both produce similar levels of cholesterol-dependent cytolysin (Macklaim et al., 2013). Therefore, the metabolic characteristics of $L$. crispatus and/or L. jensenii dominance can be defined as a healthy vaginal microenvironment. However, whether the metabolic characteristics of the non-Lactobacillus abundance of some asymptomatic women are similar to those of $L$. crispatus and/or L. jensenii dominance needs to be further explored.

The mucous layer on the surface of female genital tract epithelial cells plays an important role as the first line of defense against microbial invasion (Mirmonsef et al., 2011; Aldunate et al., 2015). When microorganisms break through the line of defense, epithelial cells use pattern recognition receptors (PPRs) to identify microorganisms to produce inflammatory factors and recruit inflammatory cells to resist microbial invasion and colonization. The dominance of Lactobacillus in the genital tract is essential, as it inhibits pathogens and maintains immune equilibrium (Smith and Ravel, 2017). Studies have found that the concentration of inflammatory factors in the vagina is very low when $L$. crispatus and L. jensenii are dominant (Kyongo et al., 2012). Lactic acid, as a metabolite derived primarily from Lactobacillus spp., is also related to reproductive tract immunity (DelgadoDiaz et al., 2019). L-lactic acid produced by Lactobacillus spp. can cause an anti-inflammatory response and inhibit the production of proinflammatory cytokines and chemokines induced by tolllike receptor (TLR) in cervical and vaginal epithelial cells at low pH (Delgado-Diaz et al., 2019). In addition, lactic acid can induce the secretion of the anti-inflammatory cytokine interleukin (IL)-10, reduce the production of the proinflammatory cytokine IL-12 in dendritic cells (DCs), and reduce the cytotoxicity of natural killer cells (Ilhan et al., 2019). The anti-inflammatory activity of lactic acid also requires the presence of organic acids produced by microorganisms to maintain vaginal health, mainly by increasing the production of the anti-inflammatory cytokine IL-1RA, inhibiting the proinflammatory signal of the IL-1 cytokine, and slightly reducing the production of the proinflammatory cytokines IL-6 and macrophage inflammatory protein 3 alpha (MIP-3 $\alpha$ ) (Delgado-Diaz et al., 2019). Therefore, the interaction between the flora, metabolites, and immunity in the healthy reproductive tract is very important for maintaining the health of the reproductive tract. When any one party is imbalanced, it will affect the balance of the reproductive tract.

\section{COMMON REPRODUCTIVE TRACT INFECTIONS}

Female genital tract infections mainly include vaginitis, cervicitis, and PID (Sherrard et al., 2018). The main cause is exogenous pathogen interference or endogenous dysbiosis (Workowski and Bolan, 2015; Song et al., 2020). At present, the relevant research on infectious diseases caused by the interaction between reproductive tract microorganisms, metabolites and the host is mainly focused on BV, Chlamydia trachomatis (C. trachomatis), and AV (Ceccarani et al., 2019). In addition, inflammation of the reproductive tract caused by bacterial flora disorders involving $\mathrm{BV}, \mathrm{AV}$, and C. trachomatis infection is closely related to adverse pregnancy outcomes and tumors (Sherrard et al., 2018). Other diseases, such as trichomoniasis (Trichomonas vaginalis), vulvovaginal candidiasis, and gonorrhea, have received less relevant research in this area and may become future research directions. Therefore, this section mainly discusses the interaction between the microorganisms, metabolites, and host immunity of three common RTIs: BV, C. trachomatis infection, and AV.

\section{BV}

$\mathrm{BV}$ is the most common vaginal microbial disorder of women of childbearing age, and can lead to adverse obstetrics and gynecological outcomes such as infertility, miscarriage, premature rupture of membranes, and premature delivery (Workowski and Bolan, 2015; Baqui et al., 2019; Peebles et al., 2019). It also increases the risk of sexually transmitted infections (Shipitsyna et al., 2020). BV is characterized by an increase in the diversity of vaginal microbiota, a decrease in Lactobacillus spp. in the vagina, and an increase in BV-related anaerobic and microaerobes (Srinivasan et al., 2015). BV-related bacteria mainly include Gardnerella, Atopobium, Mycoplasma, Megasphaera, Mobiluncus, Roseburia, Dialister., Sneathia and Prevotella spp. (McMillan et al., 2015; Ceccarani et al., 2019). However, flora analysis alone cannot distinguish between a normal vaginal environment and BV because Atopobium spp., Prevotella spp. and Mycoplasma hominis can also be detected in healthy people, therefore, the vaginal microenvironment needs to be analyzed in combination with metabolomics (Vitali et al., 2015).

$\mathrm{BV}$ is closely related to metabolites in the genital tract (Spiegel et al., 1980; Wolrath et al., 2002) (Table 2). The metabolites of amines, organic acids, short chain fatty acids (SCFAs), amino acids, nitrogenous bases and monosaccharides of BV patients are significantly different from those of healthy individuals (Vitali et al., 2015). Current studies suggest that metabolites better reflect the disease phenotype than microorganisms. Before disease symptoms appear, the appearance or disappearance of certain metabolites in the vagina has a positive or negative correlation with the metabolic function of certain microorganisms (Yeoman et al., 2013). Changes in maltose, kynurenine, nicotinate, malonate, acetate and nicotinamide adenine dinucleotide $\left(\mathrm{NAD}^{+}\right)$represent the occurrence of $\mathrm{BV}$ and can be used as metabolic biomarkers to distinguish BV from a healthy vagina (Vitali et al., 2015). When $\mathrm{BV}$ is cured, the metabolites associated with BV decrease significantly (Stanek et al., 1992; Srinivasan et al., 2015). In addition, genital tract metabolic analysis plays a prominent role in the diagnosis of BV (Watson and Reid, 2018). In 2015, McMillan et al. (2015) found that an increase in 2hydroxyisovalerate and $\gamma$-hydroxybutyrate and a decrease in lactic acid and tyrosine in the vagina are the most sensitive 
TABLE 2 | Current existing articles analyzing the correlation between the genital tract flora and metabolites in women with vaginitis.

\begin{tabular}{llll}
\hline Year & Author & \multicolumn{1}{c}{ Population } & Sampl \\
\hline BV & & & \\
2019 & (Ceccarani & Healthy women $(n=21)$, women with $B V(n=20)$ and women & Vaginal \\
& et al., 2019) & with Chlamydia trachomatis infection $(n=20)$ & swabs
\end{tabular}

2018 (Parolin et al. 2018)

Healthy women $(n=22)$, women with Chlamydia trachomatis infection $(n=20)$, and women with BV $(n=19)$

2015

(McMillan et al., Pregnant women $(n=67)$ and non-pregnant women $(n=64)$ 2015)

2015 (Srinivasan et al., 2015)

Women with BV $(n=40)$ and women with non-BV $(n=20)$

Vaginal

fluid

2015 (Vitali et al., 2015)

BV-affected patients $(n=43)$ and healthy controls $(n=37)$

2013 (Yeoman et al., Pre-menopausal women of reproductive age $(n=36)$ 2013)
Vaginal swabs

Vaginal fluid
Vaginal

fluid

CST

Metabolites

CST-IV 1) Higher levels of organic acids (i.e.: formate, pyruvate, propionate, acetate, 2-hydroxyisovalerate), amines (i.e.: trimethylamine, putrescine), amino acids (i.e.: proline and alanine) and 5-aminopentanoate 2) Lower levels of lactate, 4-hydroxyphenylacetate, phenylalanine, pi-methylhistidine, glycine, isoleucine, leucine, tryptophan, aspartate, dimethylamine, and sarcosine

CST-IV Higher levels of biogenic amines (methylamine, putrescine, trimethylamine, tyramine, desaminotyrosine), organic acids (succinate, malonate, 2-

hydroxyisovalerate, and short-chain fatty acids) and alanine

CST-IV 1) Organic acid: higher levels of 2-hydroxyisovalerate, $\gamma$ -hydroxybutyrate, 2-hydroxyglutarate and 2hydroxyisocaproate; lower levels of lactate 2) Amines: higher levels of tyramine, putrescine, and cadaverine

3) Amino acids: lower levels of tyrosine

CST-IV 1) Amino acid: higher levels of cadaverine, pipecolate, tyramine, 4-hydroxyphenylacetate, 3- (4-hydroxyphenyl) propionate, tryptamine, citrulline and putrescine; lower concentrations of arginine, ornithine, spermine and dipeptides

2) Carbohydrates: higher levels of $\mathrm{N}$-acetylneuraminate, galactose, threitol and succinate; lower levels of glucosamine, maltotriose, maltotetraose, maltopentaose, maltohexaose, lactate, fructose, and mannitol 3) NAD: lower levels of nicotinamide; higher levels of nicotinate

4) Lipids: higher levels of 12-hydroxyeicosatetraenoic acid, deoxycarnitine, 4-hydroxybutyrate and 13-hydroxyoctadecadienoic acid; lower levels of arachidonate, carnitine, ascorbic acid, acetylcarnitine, propionylcarnitine, butyrylcarnitine, glycerol and glycerol-3-phosphate

2012 (Gajer et al.,

Reproductive age women $(n=32)$ 2012)

Vaginal

lavage

fluid

Vaginal swabs
CST-IV 1) Amines: higher levels of tyramine, ethanolamine, trimethylamine, methylamine, cadaverine 2) Organic acids: higher levels of formate, malonate, succinate, pyruvate, acetate 3) Short-chain fatty acids: higher levels of propionate, butyrate, 2-hydroxyisovalerate 4) Amino acids: higher levels of proline; lower levels of tryptophan, phenylalanine, tyrosine, glutamate, isoleucine, leucine

5) Nitrogenous bases: higher levels of nicotinate, uracil; lower levels of NAD+, inosine

6) Sugars: higher levels of glucose; lower levels of maltose

7) Others: higher levels of urocanate, 2-aminoadipate, 3-methyl-2-oxovalerate; lower levels of kynurenine, snglycero-3-phosphocholine, sarcosine

CST-IV 1) Higher levels of putrescine, cadaverine, 2-methyl-2hydroxybutanoic acid, hydroxylamine, glycolic acid, tetradecanoic acid, and butyrolactone 2) Lower levels of 2,3-hydroxypropyl-2-aminoethyl phosphate, cis-11-octadecanoic acid, and ribose-5phosphate

CST-IV 1) Higher levels of succinate and acetate 2) Lower concentrations of lactate 


\begin{tabular}{|c|c|c|c|c|c|}
\hline Year & Author & Population & Sample & CST & Metabolites \\
\hline 2002 & $\begin{array}{l}\text { (Wolrath et al., } \\
\text { 2002) }\end{array}$ & $\begin{array}{l}\text { Women of childbearing age with various lower genital tract } \\
\text { disorders }(n=61)\end{array}$ & $\begin{array}{l}\text { Vaginal } \\
\text { fluid }\end{array}$ & CST-IV & Higher levels of trimethylamine \\
\hline 1980 & $\begin{array}{l}\text { (Spiegel et al., } \\
\text { 1980) }\end{array}$ & Women with non-specific vaginitis $(n=53)$ & $\begin{array}{l}\text { Vaginal } \\
\text { fluid }\end{array}$ & CST-IV & $\begin{array}{l}\text { 1) Higher levels of succinate, acetate, butyrate, and } \\
\text { propionate } \\
\text { 2) Lower levels of lactate }\end{array}$ \\
\hline \multicolumn{6}{|c|}{ Chlamydia trachomatis } \\
\hline 2018 & $\begin{array}{l}\text { (Parolin et al., } \\
\text { 2018) }\end{array}$ & $\begin{array}{l}\text { Women with Chlamydia trachomatis infection }(n=20) \text {, healthy } \\
\text { women }(n=22) \text {, and women with BV }(n=19)\end{array}$ & $\begin{array}{l}\text { Vaginal } \\
\text { swabs }\end{array}$ & CST-III & $\begin{array}{l}\text { Lower levels of tyramine, dimethylamine, cadaverine, } \\
\text { succinate, valine, isoleucine, glycine, sarcosine, } \\
\text { creatinine, 4-aminobutyrate }\end{array}$ \\
\hline 2019 & $\begin{array}{l}\text { (Ceccarani } \\
\text { et al., 2019) }\end{array}$ & $\begin{array}{l}\text { Healthy women }(n=21) \text {, women with BV }(n=20) \text { and women } \\
\text { with Chlamydia trachomatis infection }(n=20)\end{array}$ & $\begin{array}{l}\text { Vaginal } \\
\text { swabs }\end{array}$ & CST-IV & $\begin{array}{l}\text { Lower levels of lactate, certain amino acids and } \\
\text { biogenic amines }\end{array}$ \\
\hline \multicolumn{6}{|c|}{ (c) } \\
\hline 2012 & $\begin{array}{l}\text { (Gajer et al., } \\
\text { 2012) }\end{array}$ & Reproductive age women $(n=32)$ & $\begin{array}{l}\text { Vaginal } \\
\text { swabs }\end{array}$ & CST-IV & Higher levels of acetate and lactate \\
\hline
\end{tabular}

CST, Community state types; $B V$, bacterial vaginosis; $A V$, aerobic vaginitis.

and specific indicators for the diagnosis of BV. Therefore, not only the microbiota but also metabolites can be used as effective reference indicators for clinical diagnosis.

The vaginal microbiota and metabolites of BV patients are also closely related to the clinical symptoms and signs of the host. The odor of vaginal secretions in patients with BV is related to the increase in tyramine, trimethylamine, cadaverine, and putrescine and the decrease in the aromatic substances $2(5 \mathrm{H})$-furanone and 2-ethyl-4-methyl-1,3-dioxolane (Yeoman et al., 2013; Srinivasan et al., 2015; Vitali et al., 2015). Odor is also closely related to Dialister spp. (Yeoman et al., 2013; McMillan et al., 2015; Srinivasan et al., 2015). Thin and homogeneous secretions are positively related to cadaverine, and cadaverine is related to Streptococcus spp. and Mycoplasma spp. (Yeoman et al., 2013; Srinivasan et al., 2015). Clue cells are positively correlated with deoxycarnitine and pipecolate, while deoxycarnitine is positively correlated with BV-associated bacterium 1 (BVAB1), Megasphaera sp. type 2, and several Prevotella species (Srinivasan et al., 2015). Vaginal discharge is related to 2-methyl-2hydroxybutanoic acid and Mobiluncus spp. (Yeoman et al., 2013). In addition, the metabolic pathways of amino acids, carbohydrates, NAD, and lipids in the vaginal flora of $\mathrm{BV}$ patients are active and are closely related to cellular life activities (Srinivasan et al., 2015; Ceccarani et al., 2019).Therefore, understanding the interaction between the flora and metabolites of BV patients provides a basis for understanding the molecular mechanisms of microbe-microbe and microbe-host interactions (Ilhan et al., 2019).

BV-related bacteria can activate the host's genital tract immune response, but they do not cause obvious inflammatory symptoms such as redness, swelling, heat and pain (Smith and Ravel, 2017). The reason may be related to the influence of BVrelated microorganisms and their metabolites on immunity. In 2019, Delgado-Diaz et al. (2019) found that the sustained action of organic acids, metabolites of the vaginal microbiota associated with $\mathrm{BV}$, led to dysregulation of the immune response of cervical and vaginal epithelial cells in vitro. SCFAs can recruit and activate female reproductive tract innate immune cells, such as neutrophils and monocytes (Vitali et al., 2015). However, SCFAs can also inhibit the production of proinflammatory cytokines and affect the migration and phagocytic response of immune cells to regulate the immune response (Al-Mushrif et al., 2000). In addition, succinic acid produced by Prevotella spp. and Mobiluncus spp. in the genital tract can also inhibit leukocyte chemotaxis and regulate the immune response (Al-Mushrif et al., 2000; McMillan et al., 2015; Vitali et al., 2015). In 1985, Rotstein et al. (1985) demonstrated that succinic acid has the strongest chemotaxis inhibitory effect at $\mathrm{pH} 5.5$ and at concentrations of 20-30 mM. Therefore, the current research has proven that the interaction between $\mathrm{BV}$ flora, metabolites and immunity is of great significance for understanding clinical symptoms and signs. However, more research on the interaction mechanism between immunity and metabolites in BV patients is needed to confirm the influence of metabolites on flora and immunity.

\section{Chlamydia trachomatis}

In 2016, the World Health Organization announced the newest global C. trachomatis prevalence rate of $1.5-7 \%$ for women aged 15-49 years and an estimated 127 million new cases women worldwide that year (Organization, 2020). Most women infected with C. trachomatis are asymptomatic (Ceccarani et al., 2019). Approximately $10 \%$ of $C$. trachomatis infections will progress to PID without timely treatment, which will cause severe ectopic pregnancy, reproductive dysfunction and cancer (Workowski and Bolan, 2015; Idahl et al., 2020). Lactic acid is an important inhibitor of C. trachomatis infection (Gong et al., 2014). However, L. iners produces less lactic acid, so the microbiota dominated by $L$. iners increases the risk of $C$. trachomatis infection (Van Houdt et al., 2018). Similarly, BV also increases the risk of $C$. trachomatis infection due to a reduction in the lactate concentration (Shipitsyna et al., 2020). Therefore, C. trachomatis infection is greatly affected by lactic acid in the reproductive tract microenvironment.

The interactions among microorganisms, C. trachomatis and metabolites in the reproductive tract are closely related (Table 2). In 2016, Ceccarani et al. (2019) performed a combined metagenomic and metabolomics analysis on the vaginal secretions of non-pregnant Caucasians of childbearing age with risk factors for $C$. trachomatis infection. The study showed that $C$. trachomatis infection was dominated by Lactobacillus in most 
people, and L. iners was increased, and some patients had anaerobic bacteria as the dominant bacteria. Compared with healthy controls, women infected with C. trachomatis showed only slight changes in vaginal metabolites that were mainly manifested as a reduction in certain amino acids and biogenic amines (Ceccarani et al., 2019). In 2018, Parolin et al. (2018) studied the characteristics of vaginal microbes and metabolites in the case of $C$. trachomatis infection and found that vaginal valine, isoleucine, tyramine, cadaverine, and succinate in patients with $C$. trachomatis infection were significantly decreased compared with those in healthy controls, indicating that C. trachomatis may use nitrogen as the first nutrient source or that C. trachomatis may affect the nitrogen metabolism of infected host cells. There is a correlation between the vaginal microbiome, metabolites, and genital symptoms of $C$. trachomatis infection (Parolin et al., 2018). More than half of C. trachomatis-infected patients are completely asymptomatic, while symptomatic patients mainly manifest with abnormal vaginal discharge, dyspareunia, dysuria, and abnormal bleeding. The concentration of 4 -aminobutyrate is significantly different between asymptomatic and symptomatic women with $C$. trachomatis infection. However, all asymptomatic women have $L$. crispatus as the dominant bacteria in the vagina, and only half of symptomatic women have L. crispatus as the dominant bacteria (Parolin et al., 2018). Therefore, C. trachomatis infection is related to the genital tract flora, metabolites and clinical symptoms. However, the effect of 4-aminobutyrate on host immunity against $C$. trachomatis infection needs further study.

There are complicated interactions between C. trachomatis, microorganisms, genital tract metabolites and immunity (Ziklo et al., 2016b). Epithelial cells and immune cells infected by $C$. trachomatis can secrete several proinflammatory cytokines and chemokines to eliminate pathogen infection (Rasmussen et al., 1997; Johnson, 2004; Brunham and Rey-Ladino, 2005). Interferon (IFN)- $\gamma$ is an important factor that inhibits the reproduction of C. trachomatis (Shemer and Sarov, 1985). The ability to synthesize tryptophan in the IFN $\gamma$-rich infection microenvironment is an important virulence factor of the genital C. trachomatis serovars (Aiyar et al., 2014). IFN- $\gamma$ mediates the activation of host indoleamine 2,3-dioxgenase (IDO), leading to the consumption of tryptophan necessary for the growth of $C$. trachomatis and inhibiting the growth of $C$. trachomatis (Beatty et al., 1994; Aiyar et al., 2014; Olive and Sassetti, 2016; Molenaar et al., 2018). The tryptophan needed for the growth of C. trachomatis is reduced, and C. trachomatis forms a static state (Byrne et al., 1989). It is known that BV infection increases the risk of $C$. trachomatis infection. BVrelated bacteria, such as partial Prevotella species, can produce indole (Romanik et al., 2007; Sasaki-Imamura et al., 2011), which is increased in the vaginal discharge of BV patients (Lewis et al., 2014). C. trachomatis in the genital tract can use indole produced by microorganisms as a substrate to activate alternative tryptophan synthesis pathways- the $\operatorname{tr} p A, \operatorname{trp} B$ and $\operatorname{trp} R$ genes, synthesize tryptophan, and make $C$. trachomatis evade the clearance of IFN- $\gamma$ in the genital tract (Fehlner-Gardiner et al., 2002; Wood et al., 2003; Ziklo et al., 2016b). However, in patients who are coinfection with $\mathrm{BV}$ and $C$. trachomatis, the inhibitory response to IFN- $\gamma$ is not exactly the same, which may be related to the level of indole in the vaginal microenvironment (Lewis et al., 2014). In addition, the low oxygen environment formed under BV may result in insufficient energy supply for the IFN- $\gamma$ signaling pathway, which further reduces its function (Roth et al., 2010). IFN- $\gamma$ induces the production of nitric oxide and further inhibits the growth of $C$. trachomatis (Agrawal et al., 2011). The most recent in vitro experiments have confirmed that $C$. trachomatis induces the expression of ornithine decarboxylase (ODC), deprives the inducible nitric oxide synthase (iNOS) substrate arginine, and actively promotes polyamine synthesis while downregulating iNOS expression and inhibiting the activity of iNOS to reduce nitric oxide production in the host and further escape the host's innate immunity (Abu-Lubad et al., 2014; Olive and Sassetti, 2016). Studies have shown that the amino acids and sugars in the environment are critical to the ability of C. trachomatis to infect (Harper et al., 2000). However, the detailed metabolic and immune interaction mechanisms still need further study. After C. trachomatis escapes the host's immunity, the host's immune surveillance is reduced, and the environment is conducive to the growth of $C$. trachomatis, which is reactivated (Belland et al., 2003). After C. trachomatis reinfection or chronic infection, $\mathrm{T}$ helper (Th)1-, Th2- and Th17-type cells are triggered to mediate tissue destruction, fibrosis, and scarring, further leading to the progression of PID and its sequelae (Ziklo et al., 2016a; Molenaar et al., 2018).

\section{AV}

The incidence of AV in women of childbearing age is approximately $10 \%$ (Donders et al., 2017). Significantly different from BV patients and those with a normal flora, AV patients have increased aerobic bacteria or enterococci, such as Escherichia coli, Streptococcus agalactiae, Staphylococcus aureus, Staphylococcus epidermidis, Streptococcus anginosus, and Enterococcus faecalis, in the vagina (Donders et al., 2017; Tao et al., 2019; Wang et al., 2020). Studies have also shown that BV-related bacteria often appear in the vaginal flora of AV patients, which may be related to the symbiotic relationship between $\mathrm{BV}$ - and AV-related bacteria in the state of flora disorder (Wang et al., 2020). Different from the clinical symptoms and signs of BV, AV mainly manifests as foul and yellow purulent discharge, but similar to BV, it easily causes adverse obstetrics and gynecology complications that may be related to bacterial ascending infection (Donders et al., 2017).

It is known that AV-related bacteria and their metabolites are involved in the host's inflammatory state and immune response, but their correlation with host disease phenotypes and diagnostic applications have not yet been studied. Previous studies have found that when Streptococcus sp. increase in the vaginal secretions of non-pregnant women, acetate also increases (Gajer et al., 2012) (Table 2). Acetate is a SCFAs that directly activates the host's immune-inflammatory pathway and promotes the expansion of T-regulatory (Treg) cells (Olive and Sassetti, 2016; Postler and Ghosh, 2017). However, the detailed mechanism by which acetic acid is produced by Streptococcus sp. and genital tract immunity still needs to be studied. 
AV patients mainly present with a local immune imbalance in the reproductive tract caused by pathogens (Benner et al., 2018). In 2020, Budilovskaya et al. (2020) found that the expression of IL1 $\beta$, IL-6, IL-8, IL10, tumor necrosis factor- $\alpha$ (TNF $\alpha)$ and CD68 messenger ribose nucleic acids (mRNAs) in AV patients was significantly increased, and this change was related to itching or burning as well as increases in leukocytes and parabasal epithelial cells under the microscope (Smith and Ravel, 2017). Purulent vaginal discharge and vaginal redness may be related to the toxic effect of the virulence gene sag of Streptococcus anginosus on epithelial cells, leading to epithelial cell lysis (Tao et al., 2019).

The molecular mechanism of inflammatory genital tract symptoms in AV patients may be related to the interaction of metabolism and immunity. Nitric oxide plays an important role in host resistance to pathogens. Nitric oxide is synthesized by iNOS in inflammatory cells (Richardson et al., 2006; Jones et al., 2010). After the cells secrete nitric oxide, they can kill pathogens directly beside the inflammatory cells. However, Staphylococcus aureus can evade the host nitric oxide response by changing metabolism (Olive and Sassetti, 2016). Staphylococcus aureus induces the expression of flavohaemoglobin (Hmp) through the SrrAB system, quickly and enzymatically hydrolyzes nitric oxide, and resists the host's inhibitory effect on pathogens (Richardson et al., 2006); at the same time, Staphylococcus aureus upregulates L-lactate dehydrogenase 1 (Ldh1), enabling it to survive lactic acid fermentation under aerobic and anaerobic conditions (Richardson et al., 2008). The virulence of Staphylococcus aureus requires hexose produced by glycolysis, and an increase in the glucose concentration will enhance the resistance of pathogens to nitric oxide and subsequently the host immune response (Vitko et al., 2015; Olive and Sassetti, 2016).
Polyamines are toxic to Staphylococcus aureus. Staphylococcus aureus strains with arginine catabolic mobile element (ACME) encode the acetyltransferase SpeG, which makes the strains resistant to polyamines and facilitates colonization in host cells (Diep et al., 2008; Olive and Sassetti, 2016). Pathogens evade the killing effect of the host's immune system, facilitating the colonization of pathogens in the host's reproductive tract. The colonization of toxic shock syndrome toxin-1 (TSST-1) Staphylooccus aureus strains will increase the production of proinflammatory cytokines and chemokines in human vaginal epithelial cells, further destroying the mucosal barrier and increasing the penetrating effect of TSST-1, leading to severe symptoms and signs of vulvovaginitis (Pereira et al., 2013). This also explains why vaginal inflammation in $\mathrm{AV}$ is more serious than that in BV. However, previous studies have mainly focused on of BV-related bacteria, and there are few studies on AVrelated bacteria, metabolites, and immunity. Future research may reveal the significance if it is used as a future research direction.

\section{NORMAL PREGNANCY}

Unlike non-pregnant women, healthy pregnant women are affected by estrogen-progesterone, and the vaginal microflora tends to be stable from the first trimester to the third trimester, that is, the low richness and low diversity dominated by Lactobacillus spp. inhibits the growth of CST IV pathogenic bacteria such as Gardnerella vaginalis, Atopobium vaginae, Sneathia amnii, Prevotella Bivia, and Prevotella cluster 2 (MacIntyre et al., 2015; Brown et al., 2018; Serrano et al., 2019). The vaginal flora during pregnancy is less transformed, mostly between Lactobacillus species (Romero et al., 2014;

TABLE 3 | Current existing articles analyzing the correlation between the genital tract flora and metabolites in pregnant women.

\begin{tabular}{|c|c|c|c|c|c|}
\hline Year & Author & Population & Sample & $\begin{array}{l}\text { CST/ } \\
\text { microorganisms }\end{array}$ & Metabolites \\
\hline \multicolumn{6}{|c|}{ Normal pregnant women } \\
\hline 2016 & $\begin{array}{l}\text { (Prince } \\
\text { et al., } \\
2016)\end{array}$ & $\begin{array}{l}\text { Women who delivered at term }(n=27) \text {, women } \\
\text { who delivered preterm }(n=44)\end{array}$ & $\begin{array}{l}\text { Placental } \\
\text { membranes } \\
\text { swabs }\end{array}$ & $\begin{array}{l}\text { Bradyrhizobium } \\
\text { spp., streptococcus } \\
\text { thermophilus }\end{array}$ & $\begin{array}{l}\text { Term cohorts: lower levels of the amino sugar and nucleotide } \\
\text { sugar metabolism, butanoate metabolism, riboflavin } \\
\text { metabolism, and amino-benzoate degradation }\end{array}$ \\
\hline 2015 & $\begin{array}{l}\text { (McMillan } \\
\text { et al., }\end{array}$ & $\begin{array}{l}\text { Pregnant women }(n=67) \text { and non-pregnant } \\
\text { women }(n=64)\end{array}$ & Vaginal fluid & CST-I & $\begin{array}{l}\text { Similar with non-pregnant women : } \\
\text { Higher levels of succinate }\end{array}$ \\
\hline & 2015) & & & CST-IV & $\begin{array}{l}\text { Similar with non-pregnant women : } \\
\text { 1) Organic acid: higher levels of 2-hydroxyisovalerate, } \\
\gamma \text {-hydroxybutyrate, 2-hydroxyglutarate and 2- } \\
\text { hydroxyisocaproate; lower levels of lactate } \\
\text { 2) Higher levels of amines: tyramine, putrescine, and } \\
\text { cadaverine } \\
\text { 3) }\end{array}$ \\
\hline \multicolumn{6}{|c|}{ Preterm birth } \\
\hline 2016 & $\begin{array}{l}\text { (Prince } \\
\text { et al., } \\
\text { 2016) }\end{array}$ & $\begin{array}{l}\text { Women who delivered at term }(n=27) \text {, women } \\
\text { with spontaneous preterm birth }(n=44)\end{array}$ & $\begin{array}{l}\text { Placental } \\
\text { membranes } \\
\text { swabs }\end{array}$ & $\begin{array}{l}\text { Lactobacillus } \\
\text { crispatus, } \\
\text { Acinetobacter } \\
\text { johnsonii }\end{array}$ & $\begin{array}{l}\text { Preterm cohorts: higher levels of pentose phosphate pathway, } \\
\text { glycerophopholipid metabolism, and biosynthesis of the } \\
\text { siderophore group non-ribosomal peptides }\end{array}$ \\
\hline 2014 & $\begin{array}{l}\text { (Aagaard } \\
\text { et al., } \\
\text { 2014) }\end{array}$ & $\begin{array}{l}\text { Women who delivered with preterm birth }(n= \\
16), \text { women with remote antenatal infection }(n= \\
16) \text {, and controls }(n=16)\end{array}$ & $\begin{array}{l}\text { Placenta } \\
\text { tissue }\end{array}$ & Burkholderia spp. & $\begin{array}{l}\text { 1) Higher levels of methane metabolism, isoquinoline alkaloid } \\
\text { biosynthesis, and glycine/serine/threonine metabolism } \\
\text { 2) Lower levels of biotin metabolism and } \\
\text { glycosylphosphatidylinositol anchor pathways }\end{array}$ \\
\hline
\end{tabular}

CST, Community state types. 
Serrano et al., 2019). Pregnant women with CST I as the dominant bacteria have the most stable vaginal flora throughout pregnancy, followed by those with CST V, CST II, and CST IV (MacIntyre et al., 2015). The vaginal microbiota during the third trimester is similar to that of non-pregnant women. One week after delivery, estrogen decreases, and glycogen-supported Lactobacillus spp. also decreases sharply. The stability and compliance of the vaginal flora decreased significantly, and the diversity increases, especially that of CST IV, which leads to disorders of the postpartum vaginal flora and even postpartum endometritis and puerperal morbidity (DiGiulio et al., 2015; MacIntyre et al., 2015). There are also microflora in the placenta and amniotic fluid of women who experience normal-term delivery (Collado et al., 2016; NurielOhayon et al., 2016). Some studies suggest that placental bacteria may be derived from oral flora, mainly non-pathogenic symbiotic flora such as Firmicutes, Tenericutes, Proteobacteria, Bacteroidetes, and Fusobacteria phyla (Aagaard et al., 2014). The origin of the placental microbiota is also related to the migration of the intestinal flora to the fetus-placenta interface, which promotes colonization of the fetus after birth (Collado et al., 2016). However, some studies indicate that there are no microorganisms in the normal placenta and amniotic fluid, which may be caused by the contamination of laboratory reagents or equipment or by different methods used to obtaining specimens (Leiby et al., 2018; Lim et al., 2018; De Goffau et al., 2019).

Analysis of the metabolic characteristics of the vaginal microbiota revealed that the microbial metabolic activity in the first trimester is the highest to adapt to changes in pregnancy (Serrano et al., 2019) (Table 3). As pregnancy progresses, the vaginal microbiota tends to become stable, and its metabolic capacity tends to be simplified, mainly reflected in the low activity of carbohydrate metabolism, cell wall/membrane biochemical pathways, protein synthesis pathways, and nucleic acid metabolism pathways (Serrano et al., 2019). Another study also found that the carbohydrate metabolism and lipid metabolism of cervicovaginal secretions in full-term women were downregulated during the second and third trimesters (Ghartey et al., 2015). Carbohydrate metabolism was significantly downregulated, especially in the third trimester of pregnancy, and was related to the large amount of glycogen deposition and metabolization into lactic acid in a highly estrogen state (Ghartey et al., 2015). This change is conducive to the colonization of lactobacilli in the host reproductive tract and maintains the necessary acidic $\mathrm{pH}$ in the "healthy" reproductive tract. It also helps maintain the integrity of the cervix and is related to a reduction in adverse pregnancy outcomes. In women who give birth at term, the lipid metabolism of cervicovaginal secretions is significantly reduced in the third trimester, which may be related to the acidic environment inhibiting the growth of pathogenic bacteria, and the antimicrobial component of cervicovaginal secretions, methyl-4-hydroxybenzoate, increases by approximately 8.8 times from the second to the third trimester, helping maintain a stable vaginal microenvironment (Ghartey et al., 2015). The metabolic pathways of amniotic fluid and placental flora are mainly involved in membrane transport, carbohydrate metabolism, amino acid metabolism and energy metabolism, which are closely related to the life activities of the fetal placenta (Aagaard et al., 2014; Collado et al., 2016). Therefore, the metabolic function of the genital tract flora during pregnancy is of great significance for maintaining pregnancy stability.

In normal pregnancy, the mother has increased immune tolerance to fetal-expressed paternal antigens through "extended-self" antigens to maintain the growth of the fetus in the body (Bromfield et al., 2017; Deshmukh and Way, 2019). Maternal forkhead box P3 (FOXP3) Treg cells expand locally at the maternal-fetal interface and expand systemically during pregnancy to maintain allogeneic fetal tolerance (Agostinis et al., 2019; Deshmukh and Way, 2019; Ghaemi et al., 2019). Metabolites are closely related to host immunity during pregnancy. In humans, the metabolism of L-arginine is related to the temporary suppression of the maternal immune response during pregnancy (Kropf et al., 2007). The activity of arginase expressed in the fullterm placenta of pregnant women increases significantly, and the high enzyme activity leads to a decrease in its substrate L-arginine, which in turn induces the downregulation of T-cell receptor (TCR) associated $\zeta$-chain (CD3 $\zeta$ ) and the hyporesponsiveness of functional T cells (Ismail, 2018). IDO also uses a similar approach to silence $\mathrm{T}$ cells to induce and maintain immune tolerance (Kropf et al., 2007). The normal reproductive tract flora plays an important role in the establishment and consolidation of mother-placental-fetal immunity to resist the interference of external pathogenic bacteria (Mei et al., 2019). Studies have demonstrated a correlation between Bacteroides species and $\mathrm{TCR} \gamma \delta+\mathrm{T}$ cells (participating in mucosal immunity) (Ghaemi et al., 2019). The microbiota can induce the accumulation of Treg cells, which are essential for maintaining immune tolerance, timely endometrial receptivity, and correct placental implantation (Benner et al., 2018). However, dysbiosis in the reproductive genital tract can lead to immune disorders and participate in the occurrence of adverse pregnancy outcomes (Smith and Ravel, 2017). Therefore, a comprehensive interpretation of the reproductive tract microbes, metabolism, and immunity during normal pregnancy provides a reference for discovering the causes and mechanisms of adverse pregnancy outcomes (Wang et al., 2016).

\section{PREGNANCY-RELATED ADVERSE OUTCOMES}

\section{Spontaneous Abortion and Infertility}

Statistics from the Centers for Disease Control in the United States showed that among married women aged 15-44 years, 6\% had infertility and $12 \%$ had impaired fecundity, and the incidence increased yearly (Prevention, 2019). RTI is a risk factor leading to reproductive dysfunction (such as infertility, miscarriage, and repeated fertility failures), which in turn leads to a clinical pregnancy rate of only $29.7-43.3 \%$ with embryo 
transfer technology (Baker et al., 2010; Franasiak et al., 2016; Koedooder et al., 2019). For example, the prevalence of BV in infertile women is 19-28\%, while the clinical pregnancy success rate is only 8\% (Haahr et al., 2016; Bracewell-Milnes et al., 2018). This observation may be related to abnormal vaginal microbiota and pelvic pathogens (such as C. trachomatis) ascending to the upper genital tract through the cervix, leading to PID and reduced fertility (Witkin et al., 1995; Franasiak et al., 2016; Haahr et al., 2016).

The normal reproductive tract flora provides a favorable environment for embryo implantation, which can increase the success rate and live birth rate of in vitro fertilization-embryo transfer (IVFET) (Hyman et al., 2012; Sirota et al., 2014; Koedooder et al., 2019). The genital tract microbiota in females with fertility disorders is mainly manifested as a decrease in Lactobacillus spp., an increase in non-Lactobacillus spp., a high concentration of Candida spp., and an increase in the prevalence of asymptomatic BV (Franasiak et al., 2016; Babu et al., 2017; Campisciano et al., 2017; Wee et al., 2018; Koedooder et al., 2019). The live birth rate will be reduced if harmful bacteria, such as Gardnerella vaginalis, Atopobium vaginae, Acidovorax spp., Enterococcus spp., and Streptococcus spp., are found in the lower reproductive tract (Hyman et al., 2012; Haahr et al., 2016; Wee et al., 2018; Koedooder et al., 2019). Studies have shown that before spontaneous abortion, endometrial aspiration fluid has higher bacterial diversity and lower Lactobacillus abundance than before a healthy pregnancy (Moreno et al., 2020). The presence of CST IV microbiota in the endometrium is related to a significant reduction in the incidence of implantation, pregnancy, and continuous pregnancy (Moreno et al., 2016). In 2016, Verstraelen et al. (2016) performed endometrial biopsy on 19 women with fertility disorders (infertility, repeated implantation failures, and repeated miscarriages) and found that $90 \%$ of women with fertility disorders mainly had Bacteroides phylum as the dominant bacteria in their endometrium. In addition, when Gardnerella and Streptococcus genra are detected in the endometrium, they have a particularly adverse effect on reproductive outcomes (Moreno et al., 2016). The endometrium microbiota may be carried by sperm and affect the microbial composition of the female reproductive tract (Koedooder et al., 2019). For example, when the detection rate of Mycoplasma hominis, Neisseria genus, Klebsiella genus and Pseudomonas genus in semen increases, it is not only related to a low sperm concentration, abnormal sperm morphology, high semen viscosity, and oligospermia but also indirectly leads to a decline in female fertility (Ahmadi et al., 2017; Monteiro et al., 2018). Microorganisms also colonize in the follicular fluid, and the low success rate of embryo transfer is related to the colonization of Propionibacterium spp. and Streptococcus spp. in the follicular fluid (Pelzer et al., 2013). Therefore, the normal genital tract flora is of great significance to the maintenance of fertility.

Endometrial receptivity and follicle quality in people with reproductive disorders are closely related to metabolites in the reproductive tract. Lipid homeostasis is essential for maintaining health (Braga et al., 2019; Hernandez-Vargas et al., 2020). In
2019, Braga et al. (2019) analyzed the lipid metabolism of the endometrial secretions taken from patients with IVFET cycles before transplantation and found that phosphoethanolamine, phosphatidic acid, diacylglycerol, triacylglycerol, glycosyl diacylglycerol, phosphatidylcholine, neutral sphingolipid, and lysophosphatidylglycerol are possible biomarkers of endometrial receptivity and are associated with implantation failure (Altmäe et al., 2014). Follicular fluid is the microenvironment for the growth of oocytes, and the metabolism of follicular fluid indirectly affects the growth and development of oocytes (Bracewell-Milnes et al., 2017). In 2019, Song et al. (2019) conducted a targeted metabolomics analysis of the follicular fluid of patients with recurrent spontaneous abortion after IVFET treatment and found that eight metabolites, namely, dehydroepiandrosterone, lysophosphatidylcholine (lysoPC) (16:0), lysoPC(18:2), lysoPC (18:1), lysoPC(18:0), lysoPC(20:5), lysoPC(20:4), and lysoPC (20:3) were upregulated in the recurrent abortion group, and 10 metabolites, namely, phenylalanine, linoleate, oleic acid, docosahexaenoic acid, lithocholic acid, 25-hydroxyvitamin D3, hydroxycholesterol, 13-hydroxy-alpha-tocopherol, leucine, and tryptophan were downregulated. The above indicators can also predict the success rate of transplantation. Therefore, it is very meaningful to analyze metabolites in people with reproductive disorders. However the metabonomic analysis of cervicovaginal secretions in women with fertility disorders still needs more research to fully prove the role of metabolism in fertility disorders and the interaction between immunity and the flora.

Fertility dysfunction may be related to the destruction of immune tolerance caused by a decline in the number and function of Treg cells (Deshmukh and Way, 2019).Through endometrial biopsies of women with infertility in the midsecretory phase of the menstrual cycle, it was found that the expression of Foxp 3 mRNA was reduced, suggesting that the differentiation of uterine $\mathrm{T}$ cells into a Treg cell phenotype is impaired, which may lead to reduced endometrial receptivity (Jasper et al., 2006). Moreover, immunoglobulin-like transcript 4 + (ILT4+) DCs may be involved in the process of recurrent miscarriage and recurrent implantation failure induced by Foxp3 + Treg cells (Liu et al., 2018). A reduction in maternal Treg cell inhibitory ability caused by microbial infection can also cause placental inflammation, leading to the release and activation of fetal-specific maternal CD8+ T cells, which infiltrate the decidua and lead to abortion (Deshmukh and Way, 2019). The microbiota is important for basic CCL2 (monocyte chemotactic protein-1, MCP-1) secretion to control the homeostasis of plasmacytoid DCs, macrophage recruitment and polarization, and local T cell balance (Sierra-Filardi et al., 2014; Swiecki et al., 2017). DCs are a key regulator of immune tolerance during pregnancy. Patients with elevated dehydroepiandrosterone and dehydroepiandrosterone sulfate (DHEAS) in the follicular fluid have DC damage, which can cause infertility or spontaneous abortion by causing the abnormal immunity of oocytes or embryos (Song et al., 2019). When combined with a bacterial flora disorder, it may aggravate the dysfunction of DCs, and reproductive dysfunction is likely. It is known that plasma 
tryptophan metabolism is closely related to abortion (Fei et al., 2016). While BV-related bacteria are involved in the metabolism of tryptophan and a variety of amino acids (Srinivasan et al., 2015), it is necessary to further study whether genital tract bacteria and their metabolites cause an imbalance of immune tolerance, affect plasma metabolite levels and participate in the occurrence of reproductive dysfunction. Future research should focus on the local immune effects of genital tract flora and metabolites on people with reproductive dysfunction as the main research direction to explore the impact of the three interactions on reproductive disorders.

\section{Preterm Birth}

Every year, 15 million babies are born premature worldwide, accounting for approximately $11 \%$ of the live birth population (Blencowe et al., 2012). Preterm birth caused by ascending genitourinary tract infection accounts for $40-50 \%$ of all preterm births (Goldenberg et al., 2008). CST-IV vaginal microflora is closely related to premature delivery (DiGiulio et al., 2015; Dunlop et al., 2015; Workowski and Bolan, 2015; Brown et al., 2018; Han et al., 2019). Additionally, studies have confirmed that pregnant women with BV have an increased risk of premature birth (Callahan et al., 2017; Anahtar et al., 2018; Chu et al., 2018; Fettweis et al., 2019; Serrano et al., 2019). Preterm birth is the second leading cause of neonatal death (Liu et al., 2016). Premature babies are prone to diabetes, chronic inflammation and cardiovascular disease in the long term (Snyers et al., 2020). Therefore, the prevention of premature birth is the top priority of medical work.

The Human Microbiome Project Multi-Omic Microbiome Study showed that L. crispatus decreased and that BVAB1, Sneathia amnii, TM7-H1 (BVAB-TM7), and partial Prevotella species increased in the first and second trimesters of women who deliver prematurely, thus, these factors can be used as markers for predicting preterm birth (Fettweis et al., 2019). Studies have also shown that the colonization of vaginal Streptococcus agalactiae and Klebsiella pneumonia in the second trimester is significantly associated with late miscarriage and very premature delivery (before 28 weeks) (Son et al., 2018; Koedooder et al., 2019). Changes in the cervicovaginal flora of women who deliver prematurely greatly alter the metabolome and are involved in premature cervical remodeling (Table 3). Ghartey et al. (2015; 2017) found that women with symptoms of preterm birth and eventually spontaneous preterm birth (sPTB) have significant changes in cervicovaginal metabolites. Lipid metabolism and carbohydrate metabolism in the cervicovaginal secretions of women who deliver prematurely are significantly upregulated, and peptide levels are significantly reduced (Ghartey et al., 2015; Ghartey et al., 2017). Upregulation of lipid and carbohydrate pathways is associated with positive energy utilization and may be related to early cervical remodeling and SPTB microbiota utilization (Ghartey et al., 2015; Ghartey et al., 2017). A decrease in dipeptides may reflect the decreased level of proteolysis in women who deliver prematurely and changes in the activities of proteases and are associated with asymptomatic
sPTB (Ghartey et al., 2015). In addition, the level of $\mathrm{N}$ acetylneuraminate in the cervix of women who deliver prematurely increased significantly (by 4.9 times), which may be related to the increased affinity of cells for infection and participate in host immunity (Ghartey et al., 2015).

Embryo development and growth depend to a large extent on placental function, and the placental microbiome may affect fetal and pregnancy outcomes. Chorioamnionitis and intrauterine infection are closely related to premature delivery (Chu et al., 2018). However, the specific source of infection may be the ascending infection of BV bacteria (Fettweis et al., 2019), the ascending carrying of sperm (Svenstrup et al., 2003), the colonization of endometrial bacteria (Cowling et al., 1992; Chu et al., 2018), the retrograde infection of salpingitis, and the bloodborne infection of oral bacteria (Chu et al., 2018). Studies have shown that the bacteria in the uterus of women who deliver prematurely are mainly derived from vaginal bacteria, such as Burkholderia taxa, which is significantly enriched in the placenta (Goldenberg et al., 2000; Aagaard et al., 2014). The metabolic enrichment of the lipopolysaccharide biosynthetic pathway of the microbiota in the placenta may be related to the expansion and reproduction of the microbiota (Aagaard et al., 2014). The premature birth rate of women with bacteria detected in amniotic fluid is higher, and the metabolomics of the amniotic fluid of women who deliver prematurely are significantly altered, contributing to the initiation of preterm birth (Menon et al., 2014; Collado et al., 2016). Studies have shown that there are flora on the fetal membranes and that the composition of the fetal membranes is closely related to the degree of inflammation of chorioamnionitis (Prince et al., 2016). Analysis of the metabolic function of the fetal membrane microbiome revealed that a reduction in the pentose phosphate pathway and glycerophospholipid metabolism is related to chorioamnionitis, and a reduction in glycerophosopholipid metabolism will lead to an increase in the production of arachidonic acid, which is related to inflammation and prostanoid synthesis and is involved in premature birth (Prince et al., 2016).

Inflammation and antimicrobial peptide reactions involved in certain vaginal microorganisms play a role in destroying and invading cervical mucus plugs or amniotic membranes and ultimately trigger proinflammatory reactions, leading to premature delivery (Goldenberg et al., 2000; Yarbrough et al., 2015; Smith and Ravel, 2017; Strauss et al., 2018). It is known that Gardnerella vaginalis ascends to infect the amniotic membrane and irritate the cervix, leading to premature delivery. Gardnerella vaginalis may activate the NACHT, LRR and PYD domainscontaining protein 3 (NLRP3) inflammasomes through monocyte NLRs; then, NLRP3 binds to and cleaves caspase-1, induces IL-1 $\beta$, IL-18, and TNF- $\alpha$ secretion, and ultimately leads to premature delivery (Vick et al., 2014). Metabolites are involved in the occurrence and development of preterm labor. When L. iners and BV-related microorganisms are increased in the vagina, the ratio of D-type/L-type lactic acid decreases, and matrix metalloproteinase (MMP-8) increases (Witkin et al., 2013; MacIntyre et al., 2015). This process eventually leads to premature cervix maturation and ascending infection of the amniotic membrane and thus, 
premature delivery (Yoon et al., 2001). Four proinflammatory cytokines, eotaxin, IL- $1 \beta$, IL- 6 and MIP-1 $\beta$, are increased significantly in the vagina of women who deliver prematurely (Fettweis et al., 2019). BVAB1, Sneathia amnii, TM7-H1, Prevotella timonensis, and Prevotella buccalis are closely related to the levels of cytokines in vaginal secretions (Fettweis et al., 2019). Both BVAB1 and TM7-H1 can produce pyruvate, acetate, L-lactate and propionate. These SCFAs reduce antimicrobial activity and promote the production of host proinflammatory cytokines and are also involved in the occurrence of preterm labor (Fettweis et al., 2019). Therefore, there is a close correlation between the microbiota, metabolites and host immune status in reproductive tracts of women who deliver prematurely, and future researchers need to study the relevant pathogenesis. However, the relationship of microbial metabolites in the reproductive tract, preterm delivery immunity and the onset of preterm delivery still needs further exploration.

\section{GYNECOLOGICAL ONCOLOGY}

Dysbiosis is related to tumor carcinogenicity (Ilhan et al., 2019; Scott et al., 2019). An imbalance in specific microorganisms can lead to host epithelial barrier dysfunction, genome integration, genotoxicity, inflammatory activation, immune abnormalities and metabolic abnormalities, creating a microenvironment that allows tumor growth and further leading to the occurrence, development and/or transfer of gynecological malignancies (Scott et al., 2019; Laniewski et al., 2020). Among them, inflammation is the central feature of carcinogenesis and the main carcinogenic mechanism related to cancer (Scott et al., 2019). Microbial virulence factors can induce chronic inflammation in host tissues, stimulate cell proliferation, cause cell proliferation disorders, and combine with the failure of cell apoptosis to ultimately lead to a malignant phenotype (Scott et al., 2019; Laniewski et al., 2020). Metabolic changes in cancer are the core of tumorigenesis and phenotypic changes (Buckendahl et al., 2011; Zhang et al., 2012; Turkoglu et al., 2016; Hopkins and Meier, 2017; Icard et al., 2018). Human microorganisms are also involved in the formation of carcinogenic metabolites and even exert genotoxicity to cause host deoxyribonucleic acid (DNA) damage and participate in tumor carcinogenicity (Kassie et al., 2001; Scott et al., 2019). Flora disorders can also destroy the host-based anticancer immune monitoring to promote tumor development and progression (Di Pietro et al., 2018; Klein et al., 2019; Scott et al., 2019; Laniewski et al., 2020). Therefore, the balance of the microenvironment of the reproductive tract has a positive effect on maintaining the stability of the microbiota and antitumor effects.

\section{Cervical Intraepithelial Lesions and Cervical Cancer}

Cervical cancer (CC) is the most common human papillomavirus (HPV)-related malignant tumor and the fourth most common malignant tumor in women worldwide. In 2018, there were an estimated 570,000 new cases and 311,000 deaths from this disease (Bray et al., 2018). Approximately $85-90 \%$ of high-risk HPV infections can be cleared spontaneously, and only $10-15 \%$ that persist lead to cervical intraepithelial neoplasia (CIN) and invasive cervical cancer (ICC). HPV-16 and HPV-18 are the main pathogens of CC (Chase et al., 2015). The surface of the cervical mucosa is susceptible to environmental influences. When dysbiosis occurs, the local cervicovaginal microenvironment may promote the progression of malignant tumors together with HPV (Ma et al., 2014; Laniewski et al., 2018; Chorna et al., 2020).

A decrease in Lactobacillus spp. and an increase in vaginal $\mathrm{pH}$ are closely related to HPV infection, cervical lesions and CC (Laniewski et al., 2018; Ilhan et al., 2019; Laniewski et al., 2020). Cervical squamous intraepithelial lesions or CC also increase the

TABLE 4 | Current existing articles analyzing the correlation between the genital tract flora and metabolites in women with cervical intraepithelial lesions and cervical cancer.

\begin{tabular}{|c|c|c|c|c|c|}
\hline Year & Author & Population & Sample & CST & Metabolites \\
\hline 2020 & $\begin{array}{l}\text { (Borgogna } \\
\text { et al., } \\
\text { 2020) }\end{array}$ & $\begin{array}{l}\text { HPV-negative participants }(n=13) \text { and HPV-positive } \\
\text { participants }(n=26)\end{array}$ & Vaginal swabs & $\begin{array}{l}\text { CST-I } \\
\text { CST-III } \\
\text { CST-IV }\end{array}$ & $\begin{array}{l}\text { Higher concentrations of histamine, 3-n-acetyl-LL-cysteine- } \\
\text { S-yl acetaminophen, and gammaaminobutyrate } \\
\text { High levels of 3-n-acetyl-L-cysteine-S-yl acetaminophen } \\
\text { Low levels of heme, glycerophosphorylcholine, and } \\
\text { oxidized glutathione }\end{array}$ \\
\hline 2019 & $\begin{array}{l}\text { (llhan } \\
\text { et al., } \\
\text { 2019) }\end{array}$ & $\begin{array}{l}78 \text { premenopausal, non-pregnant women and grouped as } \\
\text { follows: healthy HPV-negative }(n=18) \text { and HPV-positive } \\
\text { participants }(n=11) \text {, low-grade squamous intraepithelial } \\
\text { lesions }(n=12) \text {, high-grade squamous intraepithelial lesions } \\
(n=27) \text { and invasive cervical carcinoma }(n=10)\end{array}$ & $\begin{array}{l}\text { Cervicovaginal } \\
\text { lavages and } \\
\text { vaginal swabs }\end{array}$ & CST-IV & $\begin{array}{l}\text { 1) Higher levels of cadaverine, putrescine, tyramine, } \\
\text { tryptamine, agmatine, and glutathione synthesis } \\
\text { intermediate, 2-hydroxybutyrate, branched chain amino } \\
\text { acid metabolism product, alpha-hydroxy-isovalerate, and } \\
\text { L-isoleucine metabolism product, 2-hydroxy-3-methyl- } \\
\text { valerate } \\
\text { 2) Lower levels of nucleotides adenosine and cytosine and } \\
\text { xenobiotics such as 2-keto-3-deoxy-gluconate and 1,2,3- } \\
\text { benzenetriol }\end{array}$ \\
\hline 2019 & $\begin{array}{l}\text { (Kwon } \\
\text { et al., } \\
\text { 2019) }\end{array}$ & $\begin{array}{l}\text { Normal women }(n=18) \text {, cervical intraepithelial neoplasia two } \\
\text { or three patients }(n=17) \text {, and cervical cancer patients } \\
(n=12)\end{array}$ & Cervical swabs & CST-IV & $\begin{array}{l}\text { 1) Cervical cancer patients: enriched in peptidoglycan } \\
\text { biosynthesis (ko00550) pathway } \\
\text { 2) Cervical intraeptithelia neoplasia } 2 / 3 \text { patients: enriched in } \\
\text { ko00300 (lysine biosynthesis), ko00680 (methane } \\
\text { metabolism), and ko05211 (renal cell carcinoma) }\end{array}$ \\
\hline
\end{tabular}

CST, Community state types; HPV, human papillomavirus. 
diversity of the vaginal flora, limited not only to BV-related microorganisms but also to non-BV bacteria, such as Streptococcus agalactiae, Clostridium spp., Pseudomonadales order, and Staphylococcus spp. (Klein et al., 2019; Laniewski et al., 2020). An increase in the CIN stage is also related to an increase in the diversity of the vaginal microbiota, suggesting that microorganisms play a role in the regulation of persistent viral infection and disease progression (Van Ostade et al., 2018). Compared with patients with low-grade squamous intraepithelial lesions (LSILs), Sneathia sanguinegens, Anaerococcus tetradius and Peptostreptococcus anaerobius in patients with high-grade squamous intraepithelial lesions (HSILs) are more enriched in the vagina, and Mycoplasmatales order, Pseudomonadales order, and Staphylococcus spp. are more enriched in the cervix (Mitra et al., 2015; Klein et al., 2019; Laniewski et al., 2020). Another study found that Sneathia spp. and Fusobacterium spp. exist only in women with cervical lesions or cancer but not in women without lesions (Audirac-Chalifour et al., 2016). Therefore, the presence of Sneathia in the vaginal microbiome may be a characteristic microorganism of cervical lesions and CC (Laniewski et al., 2018; Laniewski et al., 2020). Analysis of the metabolic pathways of the bacterial flora in patients with CC showed that the peptidoglycan biosynthesis (ko00550) pathway is significantly enriched (Kwon et al., 2019). Research has also found that the bacterial cell wall peptidoglycan is not only essential for maintaining the overall antiosmotic pressure of the bacteria to ensure cell survival but also participates in the occurrence of inflammation, affecting the function of host neutrophils and the innate immune response. Therefore, cervical microbes may promote the development of CC and precancerous lesions by acting as a modulators of host inflammatory pathways.

The vaginal metabolism characteristics of HPV-infected and uninfected patients are different, and the vaginal CST status drives the metabolic characteristics of HPV-infected patients (Borgogna et al., 2020) (Table 4). In vaginal CST III, HPV-infected women have higher levels of biogenic amines than HPV uninfected women (Borgogna et al., 2020). In CST IV, HPV-infected women have lower concentrations of glutathione (GSH), oxidized glutathione (GSSG), glycogen, and phospholipid-related metabolites than uninfected women. There are also differences in the metabolic characteristics of HPV infection, cervical lesions, and CC. Several researchers conducted a study on the metabolome of cervicovaginal secretions in HPV-mediated cervical tumors and found that compared with HPV-negative group, HPV-positive group, and cervical lesion group, the number and diversity of cervical vaginal metabolites in CC patients were increased (Ilhan et al., 2019). Compared with the HPV-negative group, the HPV-positive, LSIL and HSIL groups had fewer amino acids, and their metabolites in cervical and vaginal secretions and the subpathways and depletion levels under the amino acid superpathway were different (Ilhan et al., 2019; Laniewski et al., 2020). In addition, in the vulvovaginal secretions of patients with CC, volatile organic compounds, such as alkanes, and methylated alkanes are different from those of healthy women, which may be related to the oxidation of cell membrane lipids and proteins during the carcinogenic process and the production of volatile organic compounds (Rodriguez-Esquivel et al., 2018; Ilhan et al., 2019). These metabolites can be used as potential biomarkers for CC. In addition, the unique metabolic characteristics in the cervicovaginal microenvironment can assist in the diagnosis and differentiation of health, HPV infection (Borgogna et al., 2020), HSILs, LSILs, and CC (Ilhan et al., 2019). For example, long chain fatty acids, ketone bodies, steroids, ceramides, and plasmalogens can distinguish individuals with ICC from those with HPV (-).

The interaction between the host and reproductive tract microorganisms forms a metabolic network that participates in the formation of the local tumor environment during the process of continuous HPV infection and cancer progression (Ilhan et al., 2019). In HSILs and CC, the vaginal microbial community disrupts amino acid and nucleotide metabolism in a manner similar to that in BV (Ilhan et al., 2019). Compared with healthy individuals, the abundance of lipid metabolites in the vaginas of ICC patients is higher (Ilhan et al., 2019; Szewczyk et al., 2019). This phenomenon may be related to the interaction between microbes and the host, which activates the carcinogenic pathways in the tumor microenvironment and increases cell proliferation and cell membrane synthesis, thus enhancing the carcinogenic activity of the microflora. Changes in the cervicovaginal microbial community cannot only change the cervicovaginal metabolome but also further affect immunity and participate in cancer progression (Ilhan et al., 2019). For example, glycochenodeoxycholate (GCDC) is a key metabolite of host-Lactobacillus cometabolism and can inhibit vaginal flora disorders (Ilhan et al., 2019). A decrease in GCDC and Lactobacillus species in CC patients leads to a decrease in the ability to induce inflammation and toxic reactions and further leads to a weakened antitumor effect.

The interaction between immunity and metabolites forms a special tumor microenvironment. In the CIN group, the concentrations of IL-8, IL-10, and nitric oxide in cervicovaginal secretions were higher than those in the control group, indicating that these mediators play a role in the tumor immune microenvironment (Tavares-Murta et al., 2008). Since IL-8 is a Th1-type cytokine and has a proinflammatory effect and IL-10 is a Th2-type cytokine and has an anti-inflammatory effect (Fernandes et al., 2015), the interaction mechanism between nitric oxide and the two needs to be further studied. ICC patients with high genital inflammation (high IL-1 $\alpha$, IL-1 $\beta$, IL-8, MIP-1 $\beta$, CCL20, regulation on activation normal T-cell expressed and secreted (RANTES), and TNFo expression) had the strongest correlation with lipids. An increase in plasmalogens and long chain polyunsaturated fatty acids in ICC not only indicates abnormal cell metabolism but also has a proinflammatory cytokine precursors effect, inducing abnormal gene expression and disordered cytokine production (Ilhan et al., 2019). Metabolites are also closely related to CC progression and tumor cell growth. CC is characterized by an immunosuppressive microenvironment and Th2-type cytokines (Bedoya et al., 2014). In females with CC, Th2-type cytokines (IL-10 and IL-13) induce the expression of arginase (ASE), which converts L-arginine into Lornithine and polyamines, and a reduction in L-arginine is related to the downregulation of the immune response, further promoting tumor progression (Bedoya et al., 2014). Therefore, an increase in 
polyamines in the vagina flora of CST IV HPV-positive patients is a metabolic feature that HPV uses to escape host immunity and promote tumor progression (Borgogna et al., 2020). More research is needed to support the impact of HPV infection, cervical lesions, and the direct mechanism of action between the bacterial flora, metabolites and immunity in the cervicovaginal secretions of patients with CC on tumor progression and tumor metastasis.

\section{Endometrial Cancer}

In 2018, there were an estimated 382,069 new cases and 89,929 deaths related to corpus uteri cancer (Bray et al., 2018). Endometrial cancer (EC) is a perimenopausal and postmenopausal tumor, divided into two categories: type I and type II (Troisi et al., 2018). Type I EC is the most common (Troisi et al., 2018). Environmental factors, including obesity, inflammation, postmenopausal estrogen metabolism imbalance and estrogen therapy, are the main risk factors for the development of type I EC (Laniewski et al., 2020). Type II EC is rare and is mainly related to endometrial atrophy (Troisi et al., 2018). Environmental factors are related to changes in the intestinal and vaginal microbiomes. The close relationship between the flora, estrogen metabolism and obesity indicates the potential role of the microbiome in the etiology of EC (Laniewski et al., 2020). EC is also closely related to PID, and an imbalance in the vaginal flora can cause PID through ascending infection, so an imbalance in the vaginal flora may be indirectly related to EC (Ness et al., 2005; Yang et al., 2015; Champer et al., 2018).

The reproductive tract microbiota is involved in the pathogenesis of EC (Laniewski et al., 2020). In 2016, WaltherAntonio et al. (2016) analyzed the genital tract flora of 17 patients with EC, four with endometrial hyperplasia and 10 with benign uterine diseases and found that in the EC cohort, Porphyromonas sp. was common in the vagina and cervix, Bacteroides and Faecalibacterium sp. were common in the endometrium, and Bacteroides sp.was common in the ovary. The endometrial microbiota of the EC and hyperplasia cohorts was similar but differed to some degree from that of the benign cohort. The endometrial hyperplasia and benign cohorts had different microbiota structures, indicating that the microbiota plays a role in the early stages of cell transformation (WaltherAntonio et al., 2016). EC patients usually have a high vaginal $\mathrm{pH}$. The detection of vaginal Atopobium vaginae and Porphyromonas sp. combined with a high vaginal $\mathrm{pH}$ is statistically correlated with EC (Walther-Antonio et al., 2016). Studies have found that Atopobium vaginae can induce proinflammatory cytokines and antimicrobial peptides, cause chronic inflammation and local immune disorders, promote Porphyromonas sp. infection in cells, destroy normal cell regulatory functions, and ultimately lead to carcinogenic processes (Walther-Antonio et al., 2016; Laniewski et al., 2020). The link between Atopobium vaginae and Porphyromonas sp. supports the link between BV-related bacteria, immunity and EC (Laniewski et al., 2020).

EC has a unique endometrial metabolic signature. In 2017, Altadill et al. (2017) studied the metabolomics of endometrial tissue samples from $39 \mathrm{EC}$ patients and 17 healthy women and found lipids, kynurenine, endocannabinoids and RNA editing pathway disorders in EC patients. Through further research on RNA editing pathways, we found that adenosine deaminases acting on RNA2 (ADAR2) are overexpressed in EC and are positively correlated with tumor aggressiveness. ADAR2 may contribute to the carcinogenicity of EC and can be used as a potential marker for EC treatment. However, whether the genital tract flora metabolites involved in EC carcinogenesis remains to be studied. It is known that the concentration of hydroxybutyric acid in the reproductive tract of BV patients is elevated. In the intestine, SCFAs (such as hydroxybutyrate) induce Treg cells through histone deacetylases (HDACs) and exert an immunosuppressive effect in innate immune cells (McMillan et al., 2015; Chen and Stappenbeck, 2019). Whether hydroxybutyrate in the reproductive tract induces immune suppression through HDACs and promotes the growth of endometrial tumors requires further in vitro experiments.

\section{Ovarian Cancer}

Ovarian cancer (OC) is one of the deadliest malignant tumors in women and the main cause of death from gynecological malignancies (Turkoglu et al., 2016; Laniewski et al., 2020). In 2018, an estimated 295,414 new cases of OC were diagnosed worldwide, and 184,799 women died from the disease, ranking fifth among cancer-related deaths (Bray et al., 2018). More than $80 \%$ of patients have advanced disease, and the five-year overall survival rate is between 15 and 45\% (Turkoglu et al., 2016). Similar to EC, chronic infection of sexually transmitted pathogens and ascending infection of genital tract inflammation are related to the occurrence of OC (Shanmughapriya et al., 2012; Idahl et al., 2020).

In 2019, Nene et al. (2019) first published a study on the presence of abnormal uterine flora in women with OC or at risk of OC and found a strong correlation of OC or the breast cancer susceptibility gene 1 (BRCA1) mutation status with participants aged $<50$ years and those with a non-Lactobacillus dominant microbiota. Women who have used oral contraceptive pills or combined hormones for more than 5 years are more likely to have Lactobacillus dominance and a lower risk of OC than women who are using oral contraceptive pills or women who have used combined hormones for less than 5 years. Compared with the healthy surrounding ovarian tissue of the same individual, OC tissue has unique microbial characteristics (Banerjee et al., 2017). Potentially pathogenic intracellular microorganisms, such as Brucella spp., Chlamydia spp. and Mycoplasma spp., are present in $60-76 \%$ of ovarian tumors (Banerjee et al., 2017). In addition, an increase in Proteobacteria and Firmicutes phyla in ovarian tumors, especially an increase in Actinobacteria phyla, may cause double-stranded breaks by releasing bacterial toxins (such as colibactin and cytolethal distending toxin) and directly damage cellular DNA (Banerjee et al., 2017; Nene et al., 2019). In addition, several pathogenic viruses, intracellular bacteria, fungi and parasites also exist in ovarian tissue (Banerjee et al., 2017). These microorganisms may induce cancer through direct or indirect mechanisms (Laniewski et al., 2020). It is known that the integration of the HPV genome into the human genome is an important reason for the development of CC. In 2017, 
Banerjee et al. (2017) found HPV signals in the tumor tissues of OC patients, and there was also an integration phenomenon. For example, HPV16 has the largest number of viral integration sites in human chromosomes. It can be integrated into various intronic regions and genetic regions within $56 \mathrm{~kb}$ upstream of many cancer-related human genes. In addition, the coding sequence of the E1 gene of HPV18 is integrated in the intronic region of the non-coding RNA gene of the host chromosomes. All of the above factors may lead to the dysregulation of gene expression and participate in the occurrence and development of cancer (Banerjee et al., 2017). This research provides new ideas for exploring the molecular mechanism of OC.

It is known that the metabolic characteristics of OC cells, OC tissues, and ascites are significantly changed and are closely related to tumor tissue energy utilization, reproductive tract inflammation, the invasion and migration of OC cells, and the chemotherapy resistance of OC (Fong et al., 2011; Poisson et al., 2015). However, there are still few studies on the correlation between the characteristics of microbial metabolism in the reproductive tract and OC. The ovary is the end organ of the upper genital tract and is affected by the ascending bacteria of the genital tract, the bacteria of the ovary and the flora in the abdominal cavity. Whether the metabolic characteristics of the above bacteria are related to the occurrence and development of ovarian tumors and the carcinogenicity of tumors, leading to a unique tumor microenvironment, needs further research. Metabolites are closely related to tumor immunity and tumor development (Turkoglu et al., 2016; Clifford et al., 2018; Szewczyk et al., 2019). Whether the metabolites of the genital tract flora of OC patients participate in tumor immunity and host antitumor immunity, which affects the occurrence, development and metastasis of OC, still needs further research.

\section{CONCLUSION}

The host reproductive tract microenvironment includes microorganisms, metabolites and immunity, and the balance of the interactions among them is essential to maintain reproductive health. Existing research on the relationship between female reproductive tract microbes or immunity and reproductive tract inflammation, pregnancy, and tumors is becoming increasingly detailed. In contrast to research on intestinal metabolites, research on female reproductive tract metabolites is still in the preliminary stage. Moreover, the reproductive tract metabolic characteristics of $\mathrm{AV}$, reproductive dysfunction, $\mathrm{EC}$, and $\mathrm{OC}$ still need more research at present, as relevant data are lacking. Additionally, the relationship between microbial metabolites and host immunity in inflammation, pregnancy, and tumors of the female reproductive tract is relatively unclear, and it may become a new direction for future research. According to the current research, BV-related/CST IV bacteria and the microenvironment formed by the reproductive tract have the most comprehensive research on the adverse pregnancy outcomes and tumor pathogenesis. The reproductive tract microenvironment produced by BV/CST IV not only participates in the ascending infection causing PID, which leads to an increased risk of infertility, miscarriage, and premature delivery, but also participates in the increased risks of precancerous lesions and malignancy of the reproductive tract. The pathogenic mechanism of adverse pregnancy outcomes and tumor diseases in the AV microenvironment of the reproductive tract needs to be further explored. Molecular detection technology combined with immune and metabolomics can be used to better describe the function and metabolic status of the flora, infer the possible pathogenic pathways and immune response status, and analyze the complicated relationship of the local microenvironment with inflammation, pregnancy, and tumor diseases. This method is also the best way to study the pathogenic mechanism and disease characteristics of female reproductive tract inflammation, pregnancy, and tumor diseases in the reproductive tract microenvironment. The study of microorganisms, metabolites, and immunity in the microenvironment of the reproductive tract under different diseases (and then the development of targeted therapies for the above three) was the main purpose of this article. At present, there are many studies on the treatment of microorganisms with antibiotics and probiotics. Studies have proven that probiotic supplementation is very helpful in reducing the risk of inflammation, adverse pregnancy outcomes, and cancers (Nene et al., 2019; Laniewski et al., 2020) and improving the ability to respond to cancer treatments and quality of life (Postler and Ghosh, 2017; Champer et al., 2018; Laniewski et al., 2020). However, microbial therapy is still prone to relapse and associated with a high risk of recurrence. Whether targeted therapy for metabolites (Sévin et al., 2015) and immunity (Ventriglia et al., 2017; Deshmukh and Way, 2019) can be used to treat diseases or improve the effect of microbial therapy still needs further research. Therefore, studying the role and mechanism of reproductive tract flora, metabolites, and immunity in disease pathogenesis will aid in disease diagnosis and treatment and improve female reproductive health.

\section{AUTHOR CONTRIBUTIONS}

$\mathrm{HL}, \mathrm{CH}$, and FX conceived the study question, and all authors were involved in the study design. HL created the first draft of the manuscript. YZ, CW, HYL, and AF made substantial contributions to drafting the article and revising it critically. All authors contributed to the article and approved the submitted version.

\section{FUNDING}

This work was supported by Tianjin Municipal Science and Technology Commission Special Foundation for Science and Technology Major Projects in Control and Prevention of Major Diseases (Grant No. 18ZXDBSY00200), General Project of the National Natural Science Foundation of China (Grant No. 82071674) and Tianjin Health Science and Technology Project (Grant No. KJ20003). 


\section{REFERENCES}

Aagaard, K., Ma, J., Antony, K. M., Ganu, R., Petrosino, J., and Versalovic, J. (2014). The placenta harbors a unique microbiome. Sci. Transl. Med. 6, 237ra265. doi: 10.1126/scitranslmed.3008599

Abu-Lubad, M., Meyer, T. F., and Al-Zeer, M. A. (2014). Chlamydia trachomatis inhibits inducible NO synthase in human mesenchymal stem cells by stimulating polyamine synthesis. J. Immunol. 193, 2941-2951. doi: 10.4049/ jimmunol.1400377

Agostinis, C., Mangogna, A., Bossi, F., Ricci, G., Kishore, U., and Bulla, R. (2019). Uterine Immunity and Microbiota: A Shifting Paradigm. Front. Immunol. 10, 2387. doi: 10.3389/fimmu.2019.02387

Agrawal, T., Bhengraj, A. R., Vats, V., Salhan, S., and Mittal, A. (2011). Expression of TLR 2, TLR 4 and iNOS in cervical monocytes of Chlamydia trachomatisinfected women and their role in host immune response. Am. J. Reprod. Immunol. 66, 534-543. doi: 10.1111/j.1600-0897.2011.01064.x

Ahmadi, M. H., Mirsalehian, A., Sadighi Gilani, M. A., Bahador, A., and Talebi, M. (2017). Asymptomatic Infection With Mycoplasma hominis Negatively Affects Semen Parameters and Leads to Male Infertility as Confirmed by Improved Semen Parameters After Antibiotic Treatment. Urology 100, 97-102. doi: 10.1016/j.urology.2016.11.018

Aiyar, A., Quayle, A. J., Buckner, L. R., Sherchand, S. P., Chang, T. L., Zea, A. H., et al. (2014). Influence of the tryptophan-indole-IFN $\gamma$ axis on human genital Chlamydia trachomatis infection: role of vaginal co-infections. Front. Cell Infect. Microbiol. 4, 72. doi: 10.3389/fcimb.2014.00072

Aldunate, M., Srbinovski, D., Hearps, A. C., Latham, C. F., Ramsland, P. A., Gugasyan, R., et al. (2015). Antimicrobial and immune modulatory effects of lactic acid and short chain fatty acids produced by vaginal microbiota associated with eubiosis and bacterial vaginosis. Front. Physiol. 6, 164. doi: 10.3389/fphys.2015.00164

Al-Mushrif, S., Eley, A., and Jones, B. M. (2000). Inhibition of chemotaxis by organic acids from anaerobes may prevent a purulent response in bacterial vaginosis. J. Med. Microbiol. 49, 1023-1030. doi: 10.1099/0022-1317-49-11-1023

Altadill, T., Dowdy, T. M., Gill, K., Reques, A., Menon, S. S., Moiola, C. P., et al. (2017). Metabolomic and Lipidomic Profiling Identifies The Role of the RNA Editing Pathway in Endometrial Carcinogenesis. Sci. Rep. 7, 8803. doi: 10.1038/ s41598-017-09169-2

Altmäe, S., Esteban, F. J., Stavreus-Evers, A., Simón, C., Giudice, L., Lessey, B. A., et al. (2014). Guidelines for the design, analysis and interpretation of 'omics' data: focus on human endometrium. Hum. Reprod. Update 20, 12-28. doi: 10.1093/humupd/dmt048

Anahtar, M. N., Gootenberg, D. B., Mitchell, C. M., and Kwon, D. S. (2018). Cervicovaginal Microbiota and Reproductive Health: The Virtue of Simplicity. Cell Host Microbe 23, 159-168. doi: 10.1016/j.chom.2018.01.013

Audirac-Chalifour, A., Torres-Poveda, K., Bahena-Román, M., Téllez-Sosa, J., Martínez-Barnetche, J., Cortina-Ceballos, B., et al. (2016). Cervical Microbiome and Cytokine Profile at Various Stages of Cervical Cancer: A Pilot Study. PloS One 11, e0153274. doi: 10.1371/journal.pone.0153274

Babu, G., Singaravelu, B. G., Srikumar, R., Reddy, S. V., and Kokan, A. (2017). Comparative Study on the Vaginal Flora and Incidence of Asymptomatic Vaginosis among Healthy Women and in Women with Infertility Problems of Reproductive Age. J. Clin. Diagn. Res. 11, Dc18-dc22. doi: 10.7860/JCDR/ 2017/28296.10417

Baker, V. L., Jones, C. E., Cometti, B., Hoehler, F., Salle, B., Urbancsek, J., et al. (2010). Factors affecting success rates in two concurrent clinical IVF trials: an examination of potential explanations for the difference in pregnancy rates between the United States and Europe. Fertil. Steril. 94, 1287-1291. doi: 10.1016/j.fertnstert.2009.07.1673

Banerjee, S., Tian, T., Wei, Z., Shih, N., Feldman, M. D., Alwine, J. C., et al. (2017). The ovarian cancer oncobiome. Oncotarget 8, 36225-36245. doi: 10.18632/ oncotarget.16717

Baqui, A. H., Lee, A. C. C., Koffi, A. K., Khanam, R., Mitra, D. K., Dasgupta, S. K., et al. (2019). Prevalence of and risk factors for abnormal vaginal flora and its association with adverse pregnancy outcomes in a rural district in north-east Bangladesh. Acta Obstet. Gynecol. Scand. 98, 309-319. doi: 10.1111/aogs.13492

Beatty, W. L., Belanger, T. A., Desai, A. A., Morrison, R. P., and Byrne, G. I. (1994). Tryptophan depletion as a mechanism of gamma interferon-mediated chlamydial persistence. Infect. Immun. 62, 3705-3711. doi: 10.1128/ IAI.62.9.3705-3711.1994

Bedoya, A. M., Tate, D. J., Baena, A., Cordoba, C. M., Borrero, M., Pareja, R., et al. (2014). Immunosuppression in cervical cancer with special reference to arginase activity. Gynecol. Oncol. 135, 74-80. doi: 10.1016/j.ygyno.2014.07.096

Belland, R. J., Nelson, D. E., Virok, D., Crane, D. D., Hogan, D., Sturdevant, D., et al. (2003). Transcriptome analysis of chlamydial growth during IFNgamma-mediated persistence and reactivation. Proc. Natl. Acad. Sci. U.S.A. 100, 15971-15976. doi: 10.1073/pnas.2535394100

Benner, M., Ferwerda, G., Joosten, I., and Van Der Molen, R. G. (2018). How uterine microbiota might be responsible for a receptive, fertile endometrium. Hum. Reprod. Update 24, 393-415. doi: 10.1093/humupd/dmy012

Blencowe, H., Cousens, S., Oestergaard, M. Z., Chou, D., Moller, A. B., Narwal, R., et al. (2012). National, regional, and worldwide estimates of preterm birth rates in the year 2010 with time trends since 1990 for selected countries: a systematic analysis and implications. Lancet 379, 2162-2172. doi: 10.1016/S0140-6736 (12)60820-4

Borgogna, J. C., Shardell, M. D., Santori, E. K., Nelson, T. M., Rath, J. M., Glover, E. D., et al. (2020). The vaginal metabolome and microbiota of cervical HPVpositive and HPV-negative women: a cross-sectional analysis. Bjog 127, 182 192. doi: 10.1111/1471-0528.15981

Bracewell-Milnes, T., Saso, S., Abdalla, H., Nikolau, D., Norman-Taylor, J., Johnson, M., et al. (2017). Metabolomics as a tool to identify biomarkers to predict and improve outcomes in reproductive medicine: a systematic review. Hum. Reprod. Update 23, 723-736. doi: 10.1093/humupd/dmx023

Bracewell-Milnes, T., Saso, S., Nikolaou, D., Norman-Taylor, J., Johnson, M., and Thum, M. Y. (2018). Investigating the effect of an abnormal cervico-vaginal and endometrial microbiome on assisted reproductive technologies: A systematic review. Am. J. Reprod. Immunol. 80, e13037. doi: 10.1111/aji.13037

Braga, D., Borges, E.Jr., Godoy, A. T., Montani, D. A., Setti, A. S., Zanetti, B. F., et al. (2019). Lipidomic profile as a noninvasive tool to predict endometrial receptivity. Mol. Reprod. Dev. 86, 145-155. doi: 10.1002/mrd.23088

Bray, F., Ferlay, J., Soerjomataram, I., Siegel, R. L., Torre, L. A., and Jemal, A. (2018). Global cancer statistics 2018: GLOBOCAN estimates of incidence and mortality worldwide for 36 cancers in 185 countries. CA Cancer J. Clin. 68, 394-424. doi: 10.3322/caac. 21492

Bromfield, J. J., Rizo, J. A., and Ibrahim, L. A. (2017). Paternal priming of maternal tissues to optimise pregnancy success. Reprod. Fertil. Dev. 30, 50-55. doi: 10.1071/RD17345

Brown, R. G., Marchesi, J. R., Lee, Y. S., Smith, A., Lehne, B., Kindinger, L. M., et al. (2018). Vaginal dysbiosis increases risk of preterm fetal membrane rupture, neonatal sepsis and is exacerbated by erythromycin. BMC Med. 16, 9. doi: 10.1186/s12916-017-0999-x

Brunham, R. C., and Rey-Ladino, J. (2005). Immunology of Chlamydia infection: implications for a Chlamydia trachomatis vaccine. Nat. Rev. Immunol. 5, 149161. doi: $10.1038 /$ nri1551

Buckendahl, A. C., Budczies, J., Fiehn, O., Darb-Esfahani, S., Kind, T., Noske, A., et al. (2011). Prognostic impact of AMP-activated protein kinase expression in ovarian carcinoma: correlation of protein expression and GC/TOF-MS-based metabolomics. Oncol. Rep. 25, 1005-1012. doi: 10.3892/or.2011.1162

Budilovskaya, O. V., Shipitsina, E. V., Spasibova, E. V., Pereverzeva, N. A., Vorob'eva, N. E., Tsypurdeeva, N. D., et al. (2020). Differential Expression of Local Immune Response Genes in the Vagina: Implication for the Diagnosis of Vaginal Infections. Bull. Exp. Biol. Med. 168, 646-650. doi: 10.1007/s10517020-04771-3

Byrne, G. I., Carlin, J. M., Merkert, T. P., and Arter, D. L. (1989). Long-term effects of gamma interferon on chlamydia-infected host cells: microbicidal activity follows microbistasis. Infect. Immun. 57, 1318-1320. doi: 10.1128/ IAI.57.4.1318-1320.1989

Callahan, B. J., Digiulio, D. B., Goltsman, D. S. A., Sun, C. L., Costello, E. K., Jeganathan, P., et al. (2017). Replication and refinement of a vaginal microbial signature of preterm birth in two racially distinct cohorts of US women. Proc. Natl. Acad. Sci. U.S.A. 114, 9966-9971. doi: 10.1073/pnas.1705899114

Campisciano, G., Florian, F., D’eustacchio, A., Stankovic, D., Ricci, G., De Seta, F., et al. (2017). Subclinical alteration of the cervical-vaginal microbiome in women with idiopathic infertility. J. Cell Physiol. 232, 1681-1688. doi: $10.1002 /$ jcp. 25806 
Ceccarani, C., Foschi, C., Parolin, C., D’antuono, A., Gaspari, V., Consolandi, C., et al. (2019). Diversity of vaginal microbiome and metabolome during genital infections. Sci. Rep. 9, 14095. doi: 10.1038/s41598-019-50410-x

Champer, M., Wong, A. M., Champer, J., Brito, I. L., Messer, P. W., Hou, J. Y., et al. (2018). The role of the vaginal microbiome in gynaecological cancer. Bjog 125, 309-315. doi: 10.1111/1471-0528.14631

Chase, D., Goulder, A., Zenhausern, F., Monk, B., and Herbst-Kralovetz, M. (2015). The vaginal and gastrointestinal microbiomes in gynecologic cancers: a review of applications in etiology, symptoms and treatment. Gynecol. Oncol. 138, 190-200. doi: 10.1016/j.ygyno.2015.04.036

Chen, C., Song, X., Wei, W., Zhong, H., Dai, J., Lan, Z., et al. (2017). The microbiota continuum along the female reproductive tract and its relation to uterine-related diseases. Nat. Commun. 8, 875. doi: 10.1038/s41467-017-00901-0

Chen, F., and Stappenbeck, T. S. (2019). Microbiome control of innate reactivity. Curr. Opin. Immunol. 56, 107-113. doi: 10.1016/j.coi.2018.12.003

Chorna, N., Romaguera, J., and Godoy-Vitorino, F. (2020). Cervicovaginal Microbiome and Urine Metabolome Paired Analysis Reveals Niche Partitioning of the Microbiota in Patients with Human Papilloma Virus Infections. Metabolites 10, 36. doi: 10.3390/metabo10010036

Chu, D. M., Seferovic, M., Pace, R. M., and Aagaard, K. M. (2018). The microbiome in preterm birth. Best Pract. Res. Clin. Obstet. Gynaecol. 52, 103-113. doi: 10.1016/j.bpobgyn.2018.03.006

Clifford, C., Vitkin, N., Nersesian, S., Reid-Schachter, G., Francis, J. A., and Koti, M. (2018). Multi-omics in high-grade serous ovarian cancer: Biomarkers from genome to the immunome. Am. J. Reprod. Immunol. 80, e12975. doi: 10.1111/ aji. 12975

Collado, M. C., Rautava, S., Aakko, J., Isolauri, E., and Salminen, S. (2016). Human gut colonisation may be initiated in utero by distinct microbial communities in the placenta and amniotic fluid. Sci. Rep. 6, 23129. doi: 10.1038/srep23129

Consortium, H. M. P. (2012). Structure, function and diversity of the healthy human microbiome. Nature 486, 207-214. doi: 10.1038/nature11234

Cowling, P., Mccoy, D. R., Marshall, R. J., Padfield, C. J., and Reeves, D. S. (1992). Bacterial colonization of the non-pregnant uterus: a study of pre-menopausal abdominal hysterectomy specimens. Eur. J. Clin. Microbiol. Infect. Dis. 11, 204-205. doi: 10.1007/BF01967084

De Goffau, M. C., Lager, S., Sovio, U., Gaccioli, F., Cook, E., Peacock, S. J., et al. (2019). Human placenta has no microbiome but can contain potential pathogens. Nature 572, 329-334. doi: 10.1038/s41586-019-1451-5

Delgado-Diaz, D. J., Tyssen, D., Hayward, J. A., Gugasyan, R., Hearps, A. C., and Tachedjian, G. (2019). Distinct Immune Responses Elicited From Cervicovaginal Epithelial Cells by Lactic Acid and Short Chain Fatty Acids Associated With Optimal and Non-optimal Vaginal Microbiota. Front. Cell Infect. Microbiol. 9, 446. doi: 10.3389/fcimb.2019.00446

Deshmukh, H., and Way, S. S. (2019). Immunological Basis for Recurrent Fetal Loss and Pregnancy Complications. Annu. Rev. Pathol. 14, 185-210. doi: 10.1146/annurev-pathmechdis-012418-012743

Di Pietro, M., Filardo, S., Porpora, M. G., Recine, N., Latino, M. A., and Sessa, R. (2018). HPV/Chlamydia trachomatis co-infection: metagenomic analysis of cervical microbiota in asymptomatic women. New Microbiol. 41, 34-41.

Diep, B. A., Stone, G. G., Basuino, L., Graber, C. J., Miller, A., Des Etages, S. A., et al. (2008). The arginine catabolic mobile element and staphylococcal chromosomal cassette mec linkage: convergence of virulence and resistance in the USA300 clone of methicillin-resistant Staphylococcus aureus. J. Infect. Dis. 197, 1523-1530. doi: 10.1086/587907

DiGiulio, D. B., Callahan, B. J., Mcmurdie, P. J., Costello, E. K., Lyell, D. J., Robaczewska, A., et al. (2015). Temporal and spatial variation of the human microbiota during pregnancy. Proc. Natl. Acad. Sci. U.S.A. 112, 11060-11065. doi: $10.1073 /$ pnas.1502875112

Donders, G. G. G., Bellen, G., Grinceviciene, S., Ruban, K., and Vieira-Baptista, P. (2017). Aerobic vaginitis: no longer a stranger. Res. Microbiol. 168, 845-858. doi: 10.1016/j.resmic.2017.04.004

Dunlop, A. L., Mulle, J. G., Ferranti, E. P., Edwards, S., Dunn, A. B., and Corwin, E. J. (2015). Maternal Microbiome and Pregnancy Outcomes That Impact Infant Health: A Review. Adv. Neonatal Care 15, 377-385. doi: 10.1097/ ANC.0000000000000218

Fehlner-Gardiner, C., Roshick, C., Carlson, J. H., Hughes, S., Belland, R. J., Caldwell, H. D., et al. (2002). Molecular basis defining human Chlamydia trachomatis tissue tropism. A possible role for tryptophan synthase. J. Biol. Chem. 277, 26893-26903. doi: 10.1074/jbc.M203937200

Fei, H., Hou, J., Wu, Z., Zhang, L., Zhao, H., Dong, X., et al. (2016). Plasma metabolomic profile and potential biomarkers for missed abortion. BioMed. Chromatogr. 30, 1942-1952. doi: 10.1002/bmc.3770

Fernandes, J. V., Ta, D. E. M. F., Jc, D. E. A., Cobucci, R. N., Mg, D. E. C., Andrade, V. S., et al. (2015). Link between chronic inflammation and human papillomavirus-induced carcinogenesis (Review). Oncol. Lett. 9, 1015-1026. doi: $10.3892 / \mathrm{ol} .2015 .2884$

Fettweis, J. M., Serrano, M. G., Brooks, J. P., Edwards, D. J., Girerd, P. H., Parikh, H. I., et al. (2019). The vaginal microbiome and preterm birth. Nat. Med. 25, 1012-1021. doi: 10.1038/s41591-019-0450-2

Fong, M. Y., Mcdunn, J., and Kakar, S. S. (2011). Identification of metabolites in the normal ovary and their transformation in primary and metastatic ovarian cancer. PloS One 6, e19963. doi: 10.1371/journal.pone.0019963

Franasiak, J. M., Werner, M. D., Juneau, C. R., Tao, X., Landis, J., Zhan, Y., et al. (2016). Endometrial microbiome at the time of embryo transfer: nextgeneration sequencing of the $16 \mathrm{~S}$ ribosomal subunit. J. Assist. Reprod. Genet. 33, 129-136. doi: 10.1007/s10815-015-0614-Z

France, M. T., Mendes-Soares, H., and Forney, L. J. (2016). Genomic Comparisons of Lactobacillus crispatus and Lactobacillus iners Reveal Potential Ecological Drivers of Community Composition in the Vagina. Appl. Environ. Microbiol. 82, 7063-7073. doi: 10.1128/AEM.02385-16

Gajer, P., Brotman, R. M., Bai, G., Sakamoto, J., Schutte, U. M., Zhong, X., et al. (2012). Temporal dynamics of the human vaginal microbiota. Sci. Transl. Med. 4, 132ra152. doi: 10.1126/scitranslmed.3003605

Ghaemi, M. S., Digiulio, D. B., Contrepois, K., Callahan, B., Ngo, T. T. M., LeeMcmullen, B., et al. (2019). Multiomics modeling of the immunome, transcriptome, microbiome, proteome and metabolome adaptations during human pregnancy. Bioinformatics 35, 95-103. doi: 10.1093/bioinformatics/ bty537

Ghartey, J., Bastek, J. A., Brown, A. G., Anglim, L., and Elovitz, M. A. (2015). Women with preterm birth have a distinct cervicovaginal metabolome. Am. J. Obstet. Gynecol. 212, 776.e771-776.e712. doi: 10.1016/j.ajog.2015.03.052

Ghartey, J., Anglim, L., Romero, J., Brown, A., and Elovitz, M. A. (2017). Women with Symptomatic Preterm Birth Have a Distinct Cervicovaginal Metabolome. Am. J. Perinatol. 34, 1078-1083. doi: 10.1055/s-0037-1603817

Goldenberg, R. L., Hauth, J. C., and Andrews, W. W. (2000). Intrauterine infection and preterm delivery. N. Engl. J. Med. 342, 1500-1507. doi: 10.1056/ NEJM200005183422007

Goldenberg, R. L., Culhane, J. F., Iams, J. D., and Romero, R. (2008). Epidemiology and causes of preterm birth. Lancet 371, 75-84. doi: 10.1016/S0140-6736(08) 60074-4

Gong, Z., Luna, Y., Yu, P., and Fan, H. (2014). Lactobacilli inactivate Chlamydia trachomatis through lactic acid but not H2O2. PloS One 9, e107758. doi: 10.1371/journal.pone.0107758

Haahr, T., Jensen, J. S., Thomsen, L., Duus, L., Rygaard, K., and Humaidan, P. (2016). Abnormal vaginal microbiota may be associated with poor reproductive outcomes: a prospective study in IVF patients. Hum. Reprod. 31, 795-803. doi: 10.1093/humrep/dew026

Han, C., Li, H., Han, L., Wang, C., Yan, Y., Qi, W., et al. (2019). Aerobic vaginitis in late pregnancy and outcomes of pregnancy. Eur. J. Clin. Microbiol. Infect. Dis. 38, 233-239. doi: 10.1007/s10096-018-3416-2

Harper, A., Pogson, C. I., Jones, M. L., and Pearce, J. H. (2000). Chlamydial development is adversely affected by minor changes in amino acid supply, blood plasma amino acid levels, and glucose deprivation. Infect. Immun. 68, 1457-1464. doi: 10.1128/IAI.68.3.1457-1464.2000

Hernandez-Vargas, P., Munoz, M., and Dominguez, F. (2020). Identifying biomarkers for predicting successful embryo implantation: applying single to multi-OMICs to improve reproductive outcomes. Hum. Reprod. Update 26, 264-301. doi: 10.1093/humupd/dmz042

Hooper, L. V., Littman, D. R., and Macpherson, A. J. (2012). Interactions between the microbiota and the immune system. Science 336, 1268-1273. doi: 10.1126/ science. 1223490

Hopkins, M. M., and Meier, K. E. (2017). Free fatty acid receptor (FFAR) agonists inhibit proliferation of human ovarian cancer cells. Prostaglandins Leukot. Essent. Fatty Acids 122, 24-29. doi: 10.1016/j.plefa.2017.06.013 
Hyman, R. W., Herndon, C. N., Jiang, H., Palm, C., Fukushima, M., Bernstein, D., et al. (2012). The dynamics of the vaginal microbiome during infertility therapy with in vitro fertilization-embryo transfer. J. Assist. Reprod. Genet. 29, 105-115. doi: 10.1007/s10815-011-9694-6

Icard, P., Shulman, S., Farhat, D., Steyaert, J. M., Alifano, M., and Lincet, H. (2018). How the Warburg effect supports aggressiveness and drug resistance of cancer cells? Drug Resist. Update 38, 1-11. doi: 10.1016/j.drup.2018.03.001

Idahl, A., Le Cornet, C., González Maldonado, S., Waterboer, T., Bender, N., Tjønneland, A., et al. (2020). Serologic markers of Chlamydia trachomatis and other sexually transmitted infections and subsequent ovarian cancer risk: Results from the EPIC cohort. Int. J. Cancer 147, 2042-2052. doi: 10.1002/ ijc.32999

Ilhan, Z. E., Laniewski, P., Thomas, N., Roe, D. J., Chase, D. M., and Herbst-Kralovetz, M. M. (2019). Deciphering the complex interplay between microbiota, HPV, inflammation and cancer through cervicovaginal metabolic profiling. EBioMedicine 44, 675-690. doi: 10.1016/j.ebiom.2019.04.028

Ismail, A. Q. T. (2018). Does placental MDSC-mediated modulation of arginine levels help protect the foetus from auxotrophic pathogens? J. Matern. Fetal Neonatal Med. 31, 1667-1669. doi: 10.1080/14767058.2017.1319935

Jasper, M. J., Tremellen, K. P., and Robertson, S. A. (2006). Primary unexplained infertility is associated with reduced expression of the T-regulatory cell transcription factor Foxp3 in endometrial tissue. Mol. Hum. Reprod. 12, 301-308. doi: 10.1093/molehr/gal032

Johnson, R. M. (2004). Murine oviduct epithelial cell cytokine responses to Chlamydia muridarum infection include interleukin-12-p70 secretion. Infect. Immun. 72, 3951-3960. doi: 10.1128/IAI.72.7.3951-3960.2004

Jones, M. L., Ganopolsky, J. G., Labbé, A., Wahl, C., and Prakash, S. (2010). Antimicrobial properties of nitric oxide and its application in antimicrobial formulations and medical devices. Appl. Microbiol. Biotechnol. 88, 401-407. doi: 10.1007/s00253-010-2733-x

Kassie, F., Rabot, S., Kundi, M., Chabicovsky, M., Qin, H. M., and Knasmüller, S. (2001). Intestinal microflora plays a crucial role in the genotoxicity of the cooked food mutagen 2-amino-3-methylimidazo [4,5-f] quinoline. Carcinogenesis 22, 1721-1725. doi: 10.1093/carcin/22.10.1721

Klein, C., Gonzalez, D., Samwel, K., Kahesa, C., Mwaiselage, J., Aluthge, N., et al. (2019). Relationship between the Cervical Microbiome, HIV Status, and Precancerous Lesions. mBio 10, e02785-18. doi: 10.1128/mBio.02785-18

Koedooder, R., Mackens, S., Budding, A., Fares, D., Blockeel, C., Laven, J., et al. (2019). Identification and evaluation of the microbiome in the female and male reproductive tracts. Hum. Reprod. Update 25, 298-325. doi: 10.1093/humupd/ dmy048

Kropf, P., Baud, D., Marshall, S. E., Munder, M., Mosley, A., Fuentes, J. M., et al. (2007). Arginase activity mediates reversible $\mathrm{T}$ cell hyporesponsiveness in human pregnancy. Eur. J. Immunol. 37, 935-945. doi: 10.1002/eji.200636542

Kwon, M., Seo, S. S., Kim, M. K., Lee, D. O., and Lim, M. C. (2019). Compositional and Functional Differences between Microbiota and Cervical Carcinogenesis as Identified by Shotgun Metagenomic Sequencing. Cancers (Basel) 11, 309. doi: $10.3390 /$ cancers 11030309

Kyongo, J. K., Jespers, V., Goovaerts, O., Michiels, J., Menten, J., Fichorova, R. N., et al. (2012). Searching for lower female genital tract soluble and cellular biomarkers: defining levels and predictors in a cohort of healthy Caucasian women. PloS One 7, e43951. doi: 10.1371/journal.pone.0043951

Laniewski, P., Barnes, D., Goulder, A., Cui, H., Roe, D. J., Chase, D. M., et al. (2018). Linking cervicovaginal immune signatures, HPV and microbiota composition in cervical carcinogenesis in non-Hispanic and Hispanic women. Sci. Rep. 8, 7593. doi: 10.1038/s41598-018-25879-7

Laniewski, P., Ilhan, Z. E., and Herbst-Kralovetz, M. M. (2020). The microbiome and gynaecological cancer development, prevention and therapy. Nat. Rev. Urol. 17, 232-250. doi: 10.1038/s41585-020-0286-z

Leiby, J. S., Mccormick, K., Sherrill-Mix, S., Clarke, E. L., Kessler, L. R., Taylor, L. J., et al. (2018). Lack of detection of a human placenta microbiome in samples from preterm and term deliveries. Microbiome 6, 196. doi: 10.1186/ s40168-018-0575-4

Lewis, M. E., Belland, R. J., Abdelrahman, Y. M., Beatty, W. L., Aiyar, A. A., Zea, A. H., et al. (2014). Morphologic and molecular evaluation of Chlamydia trachomatis growth in human endocervix reveals distinct growth patterns. Front. Cell Infect. Microbiol. 4, 71. doi: 10.3389/fcimb.2014.00071
Lim, E. S., Rodriguez, C., and Holtz, L. R. (2018). Amniotic fluid from healthy term pregnancies does not harbor a detectable microbial community. Microbiome 6, 87. doi: $10.1186 / \mathrm{s} 40168-018-0475-7$

Liu, L., Oza, S., Hogan, D., Chu, Y., Perin, J., Zhu, J., et al. (2016). Global, regional, and national causes of under-5 mortality in 2000-15: an updated systematic analysis with implications for the Sustainable Development Goals. Lancet 388, 3027-3035. doi: 10.1016/S0140-6736(16)31593-8

Liu, S., Wei, H., Li, Y., Huang, C., Lian, R., Xu, J., et al. (2018). Downregulation of ILT4(+) dendritic cells in recurrent miscarriage and recurrent implantation failure. Am. J. Reprod. Immunol. 80, e12998. doi: 10.1111/aji.12998

Ma, Y., Madupu, R., Karaoz, U., Nossa, C. W., Yang, L., Yooseph, S., et al. (2014). Human papillomavirus community in healthy persons, defined by metagenomics analysis of human microbiome project shotgun sequencing data sets. J. Virol. 88, 4786-4797. doi: 10.1128/JVI.00093-14

MacIntyre, D. A., Chandiramani, M., Lee, Y. S., Kindinger, L., Smith, A., Angelopoulos, N., et al. (2015). The vaginal microbiome during pregnancy and the postpartum period in a European population. Sci. Rep. 5, 8988. doi: $10.1038 /$ srep08988

Macklaim, J. M., Fernandes, A. D., Di Bella, J. M., Hammond, J. A., Reid, G., and Gloor, G. B. (2013). Comparative meta-RNA-seq of the vaginal microbiota and differential expression by Lactobacillus iners in health and dysbiosis. Microbiome 1, 12. doi: 10.1186/2049-2618-1-12

McMillan, A., Rulisa, S., Sumarah, M., Macklaim, J. M., Renaud, J., Bisanz, J. E., et al. (2015). A multi-platform metabolomics approach identifies highly specific biomarkers of bacterial diversity in the vagina of pregnant and nonpregnant women. Sci. Rep. 5, 14174. doi: 10.1038/srep14174

Mei, C., Yang, W., Wei, X., Wu, K., and Huang, D. (2019). The Unique Microbiome and Innate Immunity During Pregnancy. Front. Immunol. 10, 2886. doi: $10.3389 /$ fimmu.2019.02886

Menon, R., Jones, J., Gunst, P. R., Kacerovsky, M., Fortunato, S. J., Saade, G. R., et al. (2014). Amniotic fluid metabolomic analysis in spontaneous preterm birth. Reprod. Sci. 21, 791-803. doi: 10.1177/1933719113518987

Mirmonsef, P., Gilbert, D., Zariffard, M. R., Hamaker, B. R., Kaur, A., Landay, A. L., et al. (2011). The effects of commensal bacteria on innate immune responses in the female genital tract. Am. J. Reprod. Immunol. 65, 190-195. doi: 10.1111/j.1600-0897.2010.00943.x

Mitchell, C., Manhart, L. E., Thomas, K., Fiedler, T., Fredricks, D. N., and Marrazzo, J. (2012). Behavioral predictors of colonization with Lactobacillus crispatus or Lactobacillus jensenii after treatment for bacterial vaginosis: a cohort study. Infect. Dis. Obstet. Gynecol. 2012, 706540. doi: 10.1155/2012/ 706540

Mitra, A., Macintyre, D. A., Lee, Y. S., Smith, A., Marchesi, J. R., Lehne, B., et al. (2015). Cervical intraepithelial neoplasia disease progression is associated with increased vaginal microbiome diversity. Sci. Rep. 5, 16865. doi: 10.1038/ srep 16865

Molenaar, M. C., Singer, M., and Ouburg, S. (2018). The two-sided role of the vaginal microbiome in Chlamydia trachomatis and Mycoplasma genitalium pathogenesis. J. Reprod. Immunol. 130, 11-17. doi: 10.1016/j.jri.2018.08.006

Monteiro, C., Marques, P. I., Cavadas, B., Damião, I., Almeida, V., Barros, N., et al. (2018). Characterization of microbiota in male infertility cases uncovers differences in seminal hyperviscosity and oligoasthenoteratozoospermia possibly correlated with increased prevalence of infectious bacteria. Am. J. Reprod. Immunol. 79, e12838. doi: 10.1111/aji.12838

Moreno, I., Codoner, F. M., Vilella, F., Valbuena, D., Martinez-Blanch, J. F., Jimenez-Almazan, J., et al. (2016). Evidence that the endometrial microbiota has an effect on implantation success or failure. Am. J. Obstet. Gynecol. 215, 684-703. doi: 10.1016/j.ajog.2016.09.075

Moreno, I., Garcia-Grau, I., Bau, D., Perez-Villaroya, D., Gonzalez-Monfort, M., Vilella, F., et al. (2020). The first glimpse of the endometrial microbiota in early pregnancy. Am. J. Obstet. Gynecol. 222, 296-305. doi: 10.1016/ j.ajog.2020.01.031

Nene, N. R., Reisel, D., Leimbach, A., Franchi, D., Jones, A., Evans, I., et al. (2019). Association between the cervicovaginal microbiome, BRCA1 mutation status, and risk of ovarian cancer: a case-control study. Lancet Oncol. 20, 1171-1182. doi: 10.1016/S1470-2045(19)30340-7

Ness, R. B., Kip, K. E., Hillier, S. L., Soper, D. E., Stamm, C. A., Sweet, R. L., et al. (2005). A cluster analysis of bacterial vaginosis-associated microflora and 
pelvic inflammatory disease. Am. J. Epidemiol. 162, 585-590. doi: 10.1093/aje/ kwi243

Nuriel-Ohayon, M., Neuman, H., and Koren, O. (2016). Microbial Changes during Pregnancy, Birth, and Infancy. Front. Microbiol. 7, 1031. doi: 10.3389/ fmicb.2016.01031

Olive, A. J., and Sassetti, C. M. (2016). Metabolic crosstalk between host and pathogen: sensing, adapting and competing. Nat. Rev. Microbiol. 14, 221-234. doi: 10.1038/nrmicro.2016.12

Organization, W. H. (2020). World Health Organization Global adult estimates of chlamydia, gonorrhoea, trichomoniasis and syphilis including maternal and congenital syphilis, 2016. Available at: https://www.who.int/reproductivehealth/ topics/rtis/STIs-Estimates.pdf?ua=1 (Accessed 2020).

Parolin, C., Foschi, C., Laghi, L., Zhu, C., Banzola, N., Gaspari, V., et al. (2018). Insights Into Vaginal Bacterial Communities and Metabolic Profiles of Chlamydia trachomatis Infection: Positioning Between Eubiosis and Dysbiosis. Front. Microbiol. 9, 600. doi: 10.3389/fmicb.2018.00600

Peebles, K., Velloza, J., Balkus, J. E., Mcclelland, R. S., and Barnabas, R. V. (2019). High Global Burden and Costs of Bacterial Vaginosis: A Systematic Review and MetaAnalysis. Sex Transm. Dis. 46, 304-311. doi: 10.1097/OLQ.0000000000000972

Pelzer, E. S., Allan, J. A., Waterhouse, M. A., Ross, T., Beagley, K. W., and Knox, C. L. (2013). Microorganisms within human follicular fluid: effects on IVF. PloS One 8, e59062. doi: 10.1371/journal.pone.0059062

Pereira, N., Edlind, T. D., Schlievert, P. M., and Nyirjesy, P. (2013). Vaginal toxic shock reaction triggering desquamative inflammatory vaginitis. J. Low. Genit. Tract Dis. 17, 88-91. doi: 10.1097/LGT.0b013e3182656991

Poisson, L. M., Munkarah, A., Madi, H., Datta, I., Hensley-Alford, S., Tebbe, C., et al. (2015). A metabolomic approach to identifying platinum resistance in ovarian cancer. J. Ovarian Res. 8, 13. doi: 10.1186/s13048-015-0140-8

Postler, T. S., and Ghosh, S. (2017). Understanding the Holobiont: How Microbial Metabolites Affect Human Health and Shape the Immune System. Cell Metab. 26, 110-130. doi: 10.1016/j.cmet.2017.05.008

Prevention, C.F.D.C.A. (2019). Infertility Frequently Asked Questions [Online]. Centers for Disease Control and Prevention. Available at: https://www.cdc.gov/ reproductivehealth/infertility/index.htm (Accessed January 16 2019).

Prince, A. L., Ma, J., Kannan, P. S., Alvarez, M., Gisslen, T., Harris, R. A., et al. (2016). The placental membrane microbiome is altered among subjects with spontaneous preterm birth with and without chorioamnionitis. Am. J. Obstet. Gynecol. 214, 627.e621-627.e616. doi: 10.1016/j.ajog.2016.01.193

Pruski, P., Lewis, H. V., Lee, Y. S., Marchesi, J. R., Bennett, P. R., Takats, Z., et al. (2018). Assessment of microbiota:host interactions at the vaginal mucosa interface. Methods 149, 74-84. doi: 10.1016/j.ymeth.2018.04.022

Rasmussen, S. J., Eckmann, L., Quayle, A. J., Shen, L., Zhang, Y. X., Anderson, D. J., et al. (1997). Secretion of proinflammatory cytokines by epithelial cells in response to Chlamydia infection suggests a central role for epithelial cells in chlamydial pathogenesis. J. Clin. Invest. 99, 77-87. doi: 10.1172/JCI119136

Ravel, J., Gajer, P., Abdo, Z., Schneider, G. M., Koenig, S. S., Mcculle, S. L., et al. (2011). Vaginal microbiome of reproductive-age women. Proc. Natl. Acad. Sci. U.S.A. 108 Suppl 1, 4680-4687. doi: 10.1073/pnas.1002611107

Richardson, A. R., Dunman, P. M., and Fang, F. C. (2006). The nitrosative stress response of Staphylococcus aureus is required for resistance to innate immunity. Mol. Microbiol. 61, 927-939. doi: 10.1111/j.1365-2958.2006.05290.x

Richardson, A. R., Libby, S. J., and Fang, F. C. (2008). A nitric oxide-inducible lactate dehydrogenase enables Staphylococcus aureus to resist innate immunity. Science 319, 1672-1676. doi: 10.1126/science.1155207

Rodriguez-Esquivel, M., Rosales, J., Castro, R., Apresa-Garcia, T., Garay, O., Romero-Morelos, P., et al. (2018). Volatolome of the Female Genitourinary Area: Toward the Metabolome of Cervical Cancer. Arch. Med. Res. 49, 27-35. doi: 10.1016/j.arcmed.2018.04.004

Romanik, M., Martirosian, G., Wojciechowska-Wieja, A., Cieślik, K., and Kaźmierczak, W. (2007). [Co-occurence of indol-producing bacterial strains in the vagina of women infected with Chlamydia trachomatis]. Ginekol. Pol. 78, 611-615.

Romero, R., Hassan, S. S., Gajer, P., Tarca, A. L., Fadrosh, D. W., Nikita, L., et al. (2014). The composition and stability of the vaginal microbiota of normal pregnant women is different from that of non-pregnant women. Microbiome 2, 4. doi: 10.1186/2049-2618-2-4

Roth, A., König, P., Van Zandbergen, G., Klinger, M., Hellwig-Bürgel, T., Däubener, W., et al. (2010). Hypoxia abrogates antichlamydial properties of
IFN- $\gamma$ in human fallopian tube cells in vitro and ex vivo. Proc. Natl. Acad. Sci. U.S.A. 107, 19502-19507. doi: 10.1073/pnas.1008178107

Rotstein, O. D., Pruett, T. L., Fiegel, V. D., Nelson, R. D., and Simmons, R. L. (1985). Succinic acid, a metabolic by-product of Bacteroides species, inhibits polymorphonuclear leukocyte function. Infect. Immun. 48, 402-408. doi: 10.1128/IAI.48.2.402-408.1985

Sasaki-Imamura, T., Yoshida, Y., Suwabe, K., Yoshimura, F., and Kato, H. (2011). Molecular basis of indole production catalyzed by tryptophanase in the genus Prevotella. FEMS Microbiol. Lett. 322, 51-59. doi: 10.1111/j.1574-6968.2011.02329.x

Scott, A. J., Alexander, J. L., Merrifield, C. A., Cunningham, D., Jobin, C., Brown, R., et al. (2019). International Cancer Microbiome Consortium consensus statement on the role of the human microbiome in carcinogenesis. Gut 68, 1624-1632. doi: 10.1136/gutjnl-2019-318556

Serrano, M. G., Parikh, H. I., Brooks, J. P., Edwards, D. J., Arodz, T. J., Edupuganti, L., et al. (2019). Racioethnic diversity in the dynamics of the vaginal microbiome during pregnancy. Nat. Med. 25, 1001-1011. doi: 10.1038/s41591-019-0465-8

Sévin, D. C., Kuehne, A., Zamboni, N., and Sauer, U. (2015). Biological insights through nontargeted metabolomics. Curr. Opin. Biotechnol. 34, 1-8. doi: 10.1016/j.copbio.2014.10.001

Shanmughapriya, S., Senthilkumar, G., Vinodhini, K., Das, B. C., Vasanthi, N., and Natarajaseenivasan, K. (2012). Viral and bacterial aetiologies of epithelial ovarian cancer. Eur. J. Clin. Microbiol. Infect. Dis. 31, 2311-2317. doi: 10.1007/s10096-012-1570-5

Shemer, Y., and Sarov, I. (1985). Inhibition of growth of Chlamydia trachomatis by human gamma interferon. Infect. Immun. 48, 592-596. doi: 10.1128/ IAI.48.2.592-596.1985

Sherrard, J., Wilson, J., Donders, G., Mendling, W., and Jensen, J. S. (2018). 2018 European (IUSTI/WHO) International Union against sexually transmitted infections (IUSTI) World Health Organisation (WHO) guideline on the management of vaginal discharge. Int. J. STD AIDS 29, 1258-1272. doi: $10.1177 / 0956462418785451$

Shipitsyna, E., Khusnutdinova, T., Budilovskaya, O., Krysanova, A., Shalepo, K., Savicheva, A., et al. (2020). Bacterial vaginosis-associated vaginal microbiota is an age-independent risk factor for Chlamydia trachomatis, Mycoplasma genitalium and Trichomonas vaginalis infections in low-risk women, St. Petersburg, Russia. Eur. J. Clin. Microbiol. Infect. Dis. 39, 1221-1230. doi: 10.1007/s10096-020-03831-w

Sierra-Filardi, E., Nieto, C., Domínguez-Soto, A., Barroso, R., Sánchez-Mateos, P., Puig-Kroger, A., et al. (2014). CCL2 shapes macrophage polarization by GMCSF and M-CSF: identification of CCL2/CCR2-dependent gene expression profile. J. Immunol. 192, 3858-3867. doi: 10.4049/jimmunol.1302821

Sirota, I., Zarek, S. M., and Segars, J. H. (2014). Potential influence of the microbiome on infertility and assisted reproductive technology. Semin. Reprod. Med. 32, 35-42. doi: 10.1055/s-0033-1361821

Smith, S. B., and Ravel, J. (2017). The vaginal microbiota, host defence and reproductive physiology. J. Physiol. 595, 451-463. doi: 10.1113/JP271694

Snyers, D., Lefebvre, C., Viellevoye, R., and Rigo, V. (2020). [Late preterm : high risk newborns despite appearances]. Rev. Med. Liege 75, 105-110.

Son, K. A., Kim, M., Kim, Y. M., Kim, S. H., Choi, S. J., Oh, S. Y., et al. (2018). Prevalence of vaginal microorganisms among pregnant women according to trimester and association with preterm birth. Obstet. Gynecol. Sci. 61, 38-47. doi: 10.5468/ogs.2018.61.1.38

Song, J., Wang, X., Guo, Y., Yang, Y., Xu, K., Wang, T., et al. (2019). Novel highcoverage targeted metabolomics method (SWATHtoMRM) for exploring follicular fluid metabolome alterations in women with recurrent spontaneous abortion undergoing in vitro fertilization. Sci. Rep. 9, 10873. doi: 10.1038/ s41598-019-47370-7

Song, S. D., Acharya, K. D., Zhu, J. E., Deveney, C. M., Walther-Antonio, M. R. S., Tetel, M. J., et al. (2020). Daily Vaginal Microbiota Fluctuations Associated with Natural Hormonal Cycle, Contraceptives, Diet, and Exercise. $m S p h e r e 5$, e00593-20. doi: 10.1128/mSphere.00593-20

Spiegel, C. A., Amsel, R., Eschenbach, D., Schoenknecht, F., and Holmes, K. K. (1980). Anaerobic bacteria in nonspecific vaginitis. N. Engl. J. Med. 303, 601607. doi: 10.1056/NEJM198009113031102

Srinivasan, S., Morgan, M. T., Fiedler, T. L., Djukovic, D., Hoffman, N. G., Raftery, D., et al. (2015). Metabolic signatures of bacterial vaginosis. mBio 6, e00204-15. doi: $10.1128 / \mathrm{mBio} .00204-15$ 
Stanek, R., Gain, R. E., Glover, D. D., and Larsen, B. (1992). High performance ion exclusion chromatographic characterization of the vaginal organic acids in women with bacterial vaginosis. BioMed. Chromatogr. 6, 231-235. doi: 10.1002/bmc.1130060506

Strauss, J. F., Romero, R., Gomez-Lopez, N., Haymond-Thornburg, H., Modi, B. P., Teves, M. E., et al. (2018). Spontaneous preterm birth: advances toward the discovery of genetic predisposition. Am. J. Obstet. Gynecol. 218, 294314.e292. doi: 10.1016/j.ajog.2017.12.009

Svenstrup, H. F., Fedder, J., Abraham-Peskir, J., Birkelund, S., and Christiansen, G. (2003). Mycoplasma genitalium attaches to human spermatozoa. Hum. Reprod. 18, 2103-2109. doi: 10.1093/humrep/deg392

Swiecki, M., Miller, H. L., Sesti-Costa, R., Cella, M., Gilfillan, S., and Colonna, M. (2017). Microbiota induces tonic CCL2 systemic levels that control pDC trafficking in steady state. Mucosal Immunol. 10, 936-945. doi: 10.1038/ mi.2016.99

Szewczyk, G., Maciejewski, T. M., and Szukiewicz, D. (2019). Current progress in the inflammatory background of angiogenesis in gynecological cancers. Inflammation Res. 68, 247-260. doi: 10.1007/s00011-019-01215-1

Tao, Z., Zhang, L., Zhang, Q., Lv, T., Chen, R., Wang, L., et al. (2019). The Pathogenesis Of Streptococcus anginosus In Aerobic Vaginitis. Infect. Drug Resist. 12, 3745-3754. doi: 10.2147/IDR.S227883

Tavares-Murta, B. M., De Resende, A. D., Cunha, F. Q., and Murta, E. F. (2008). Local profile of cytokines and nitric oxide in patients with bacterial vaginosis and cervical intraepithelial neoplasia. Eur. J. Obstet. Gynecol. Reprod. Biol. 138, 93-99. doi: 10.1016/j.ejogrb.2007.06.015

Troisi, J., Sarno, L., Landolfi, A., Scala, G., Martinelli, P., Venturella, R., et al. (2018). Metabolomic Signature of Endometrial Cancer. J. Proteome Res. 17, 804-812. doi: 10.1021/acs.jproteome.7b00503

Turkoglu, O., Zeb, A., Graham, S., Szyperski, T., Szender, J. B., Odunsi, K., et al. (2016). Metabolomics of biomarker discovery in ovarian cancer: a systematic review of the current literature. Metabolomics 12, 60. doi: 10.1007/s11306-016-0990-0

Van Der Veer, C., Hertzberger, R. Y., Bruisten, S. M., Tytgat, H. L. P., Swanenburg, J., De Kat Angelino-Bart, A., et al. (2019). Comparative genomics of human Lactobacillus crispatus isolates reveals genes for glycosylation and glycogen degradation: implications for in vivo dominance of the vaginal microbiota. Microbiome 7, 49. doi: 10.1186/s40168-019-0667-9

Van Houdt, R., Ma, B., Bruisten, S. M., Speksnijder, A., Ravel, J., and De Vries, H. J. C. (2018). Lactobacillus iners-dominated vaginal microbiota is associated with increased susceptibility to Chlamydia trachomatis infection in Dutch women: a case-control study. Sex Transm. Infect. 94, 117-123. doi: 10.1136/sextrans-2017-053133

Van Ostade, X., Dom, M., Tjalma, W., and Van Raemdonck, G. (2018). Candidate biomarkers in the cervical vaginal fluid for the (self-)diagnosis of cervical precancer. Arch. Gynecol. Obstet. 297, 295-311. doi: 10.1007/s00404-017-4587-2

Ventriglia, J., Paciolla, I., Pisano, C., Cecere, S. C., Di Napoli, M., Tambaro, R., et al. (2017). Immunotherapy in ovarian, endometrial and cervical cancer: State of the art and future perspectives. Cancer Treat Rev. 59, 109-116. doi: 10.1016/ j.ctrv.2017.07.008

Verstraelen, H., Vilchez-Vargas, R., Desimpel, F., Jauregui, R., Vankeirsbilck, N., Weyers, S., et al. (2016). Characterisation of the human uterine microbiome in non-pregnant women through deep sequencing of the V1-2 region of the $16 \mathrm{~S}$ rRNA gene. PeerJ 4, e1602. doi: 10.7717/peerj.1602

Vick, E. J., Park, H. S., Huff, K. A., Brooks, K. M., Farone, A. L., and Farone, M. B. (2014). Gardnerella vaginalis triggers NLRP3 inflammasome recruitment in THP-1 monocytes. J. Reprod. Immunol. 106, 67-75. doi: 10.1016/ j.jri.2014.08.005

Vitali, B., Cruciani, F., Picone, G., Parolin, C., Donders, G., and Laghi, L. (2015). Vaginal microbiome and metabolome highlight specific signatures of bacterial vaginosis. Eur. J. Clin. Microbiol. Infect. Dis. 34, 2367-2376. doi: 10.1007/ s10096-015-2490-y

Vitko, N. P., Spahich, N. A., and Richardson, A. R. (2015). Glycolytic dependency of high-level nitric oxide resistance and virulence in Staphylococcus aureus. mBio 6, e00045-15. doi: 10.1128/mBio.00045-15

Walther-Antonio, M. R., Chen, J., Multinu, F., Hokenstad, A., Distad, T. J., Cheek, E. H., et al. (2016). Potential contribution of the uterine microbiome in the development of endometrial cancer. Genome Med. 8, 122. doi: 10.1186/s13073-016-0368-y

Wang, Q., Wurtz, P., Auro, K., Makinen, V. P., Kangas, A. J., Soininen, P., et al. (2016). Metabolic profiling of pregnancy: cross-sectional and longitudinal evidence. BMC Med. 14, 205. doi: 10.1186/s12916-016-0733-0
Wang, C., Fan, A., Li, H., Yan, Y., Qi, W., Wang, Y., et al. (2020). Vaginal bacterial profiles of aerobic vaginitis: a case-control study. Diagn. Microbiol. Infect. Dis. 96, 114981. doi: 10.1016/j.diagmicrobio.2019.114981

Watson, E., and Reid, G. (2018). Metabolomics as a clinical testing method for the diagnosis of vaginal dysbiosis. Am. J. Reprod. Immunol. 80, e12979. doi: 10.1111/aji.12979

Wee, B. A., Thomas, M., Sweeney, E. L., Frentiu, F. D., Samios, M., Ravel, J., et al. (2018). A retrospective pilot study to determine whether the reproductive tract microbiota differs between women with a history of infertility and fertile women. Aust. N. Z. J. Obstet. Gynaecol. 58, 341-348. doi: 10.1111/ajo.12754

Witkin, S. S., Kligman, I., Grifo, J. A., and Rosenwaks, Z. (1995). Chlamydia trachomatis detected by polymerase chain reaction in cervices of culturenegative women correlates with adverse in vitro fertilization outcome. J. Infect. Dis. 171, 1657-1659. doi: 10.1093/infdis/171.6.1657

Witkin, S. S., Mendes-Soares, H., Linhares, I. M., Jayaram, A., Ledger, W. J., and Forney, L. J. (2013). Influence of vaginal bacteria and D- and L-lactic acid isomers on vaginal extracellular matrix metalloproteinase inducer: implications for protection against upper genital tract infections. mBio 4, e00460-13. doi: 10.1128/mBio.00460-13

Wolrath, H., Boren, H., Hallen, A., and Forsum, U. (2002). Trimethylamine content in vaginal secretion and its relation to bacterial vaginosis. Apmis 110, 819-824. doi: 10.1034/j.1600-0463.2002.1101108.x

Wood, H., Fehlner-Gardner, C., Berry, J., Fischer, E., Graham, B., Hackstadt, T., et al. (2003). Regulation of tryptophan synthase gene expression in Chlamydia trachomatis. Mol. Microbiol. 49, 1347-1359. doi: 10.1046/j.13652958.2003.03638.x

Workowski, K. A., and Bolan, G. A. (2015). Sexually transmitted diseases treatment guidelines 2015. MMWR Recomm. Rep. 64, 1-137.

Yang, T. K., Chung, C. J., Chung, S. D., Muo, C. H., Chang, C. H., and Huang, C. Y. (2015). Risk of Endometrial Cancer in Women With Pelvic Inflammatory Disease: A Nationwide Population-Based Retrospective Cohort Study. Medicine (Baltimore) 94, e1278. doi: 10.1097/MD.0000000000001278

Yarbrough, V. L., Winkle, S., and Herbst-Kralovetz, M. M. (2015). Antimicrobial peptides in the female reproductive tract: a critical component of the mucosal immune barrier with physiological and clinical implications. Hum. Reprod. Update 21, 353-377. doi: 10.1093/humupd/dmu065

Yeoman, C. J., Thomas, S. M., Miller, M. E., Ulanov, A. V., Torralba, M., Lucas, S., et al. (2013). A multi-omic systems-based approach reveals metabolic markers of bacterial vaginosis and insight into the disease. PloS One 8, e56111. doi: 10.1371/journal.pone.0056111

Yoon, B. H., Oh, S. Y., Romero, R., Shim, S. S., Han, S. Y., Park, J. S., et al. (2001). An elevated amniotic fluid matrix metalloproteinase-8 level at the time of midtrimester genetic amniocentesis is a risk factor for spontaneous preterm delivery. Am. J. Obstet. Gynecol. 185, 1162-1167. doi: 10.1067/ mob.2001.117678

Zhang, T., Wu, X., Yin, M., Fan, L., Zhang, H., Zhao, F., et al. (2012). Discrimination between malignant and benign ovarian tumors by plasma metabolomic profiling using ultra performance liquid chromatography/mass spectrometry. Clin. Chim. Acta 413, 861-868. doi: 10.1016/j.cca.2012.01.026

Ziklo, N., Huston, W. M., Hocking, J. S., and Timms, P. (2016a). Chlamydia trachomatis Genital Tract Infections: When Host Immune Response and the Microbiome Collide. Trends Microbiol. 24, 750-765. doi: 10.1016/ j.tim.2016.05.007

Ziklo, N., Huston, W. M., Taing, K., Katouli, M., and Timms, P. (2016b). In vitro rescue of genital strains of Chlamydia trachomatis from interferon- $\gamma$ and tryptophan depletion with indole-positive, but not indole-negative Prevotella spp. BMC Microbiol. 16, 286. doi: 10.1186/s12866-016-0903-4

Conflict of Interest: The authors declare that the research was conducted in the absence of any commercial or financial relationships that could be construed as a potential conflict of interest.

Copyright (c) $2020 \mathrm{Li}$, Zang, Wang, Li, Fan, Han and Xue. This is an open-access article distributed under the terms of the Creative Commons Attribution License (CC BY). The use, distribution or reproduction in other forums is permitted, provided the original author(s) and the copyright owner(s) are credited and that the original publication in this journal is cited, in accordance with accepted academic practice. No use, distribution or reproduction is permitted which does not comply with these terms. 